\title{
Recent Bairdiinae (Crustacea, Ostracoda) from the Solomon Islands
}

\author{
ROSEMARY TITTERTON ${ }^{1}$ \& ROBIN WHATLEY ${ }^{2}$ \\ ${ }^{1}$ Robertson Research International Limited, Llandudno, Gwynedd \\ ${ }^{2}$ Micropalaeontology Division, Department Geology, \\ University College of Wales, Aberystwyth, Dyfed
}

\begin{abstract}
The Bairdiinae of the littoral and inner shelf of the Solomon Islands are both abundant and diverse. A total of 21 species have been recovered of which 13 are described as new 2 further species are left in open nomenclature. The new genus Mydionobairdia is erected, based on Triebelina schyroconcha Maddocks, 1969. The new species are: Bairdoppilata paraalcyonicola, B paracratericola, Neonesidea paragierloffi, $N$. vscripta, $N$.? crepidula, N.? rara, Paranesidea bipustulosa, $P$. corbita, $P$. equipunctata, $P$. petalona, $P$. stricta, $P$.? confusa and $P$.? paucipunctata. Some of the difficulties involved in distinguishing species of Neonesidea and Paranesidea are discussed.
\end{abstract}

\section{INTRODUCTION}

Although there has been a considerable number of recent studies on the Ostracoda of the Indo-Pacific, the fauna of the Solomon Islands remains virtually unknown despite the zoogeographical importance of this region stituated as it is between the Polynesian, Indonesian and Australasian regions. The present paper is the first in a series in which this fauna will be described. Harding (1962) described five new nonmarine species recovered from the gut of fish. Apart from this, the only published work is by Whatley \& Titterton (1981) who describe two new species and a new genus from marine environments. However, three unpublished theses produced at Aberystwyth reveal more than 170 Miocene to Recent species (Hughes, 1977a MS; Williams, 1980 MS; Titterton, 1984 MS).

This study is based on a series of sediment samples collected using a simple pipe dredge or by diving, by $\mathrm{G}$. W. Hughes in Honiara Bay (samples 13-65) and by C. C. Turner in the same area (Samples 1-5). Their location and approximate depth is given in Fig. 2. An additional six samples (samples OS1-OS6) were collected by Turner from the northwestern coast of Shortland Island (Fig. 3). These samples from Shortland Island and samples 1-5 from Honiara Bay were the only ones to be preserved in buffered formalin.

Type specimens prefixed 1986. Numbers 438 to 500 are deposited in the collections of the Zoology Department, British Museum (Natural History). Specimen numbers prefixed RT/SIR (Rosemary Titterton/Solomon Islands Recent) are deposited in the Mircropalaeontology Museum, Department Geology, University College of Wales, Aberystwyth.

\section{THE BAIRDIINAE}

This subfamily are an important and often dominant group in shallow, tropical and sub-tropical seas, particularly in reef and reef- associated environments, where both their diversity and incidence reach high levels. They are particularly well represented in the Solomon Islands and dominate many of the sediment samples.

Recent members of this group were revised by Maddocks (1969), who proposed two new genera, Neonesidea and Paranesidea, which, together with Bairdoppilata Coryell, Sample \& Jennings, 1935 and Triebelina Bold, 1946, were used to accommodate many species which had previously been referred to Bairdia McCoy, 1844, which genus Maddocks confined to the Upper Palaeozoic.

In our study of the Bairdiinae of the Solomon Islands, some difficulty was encountered in accommodating certain species within established genera. For example, some species which seem closest to Noensidea

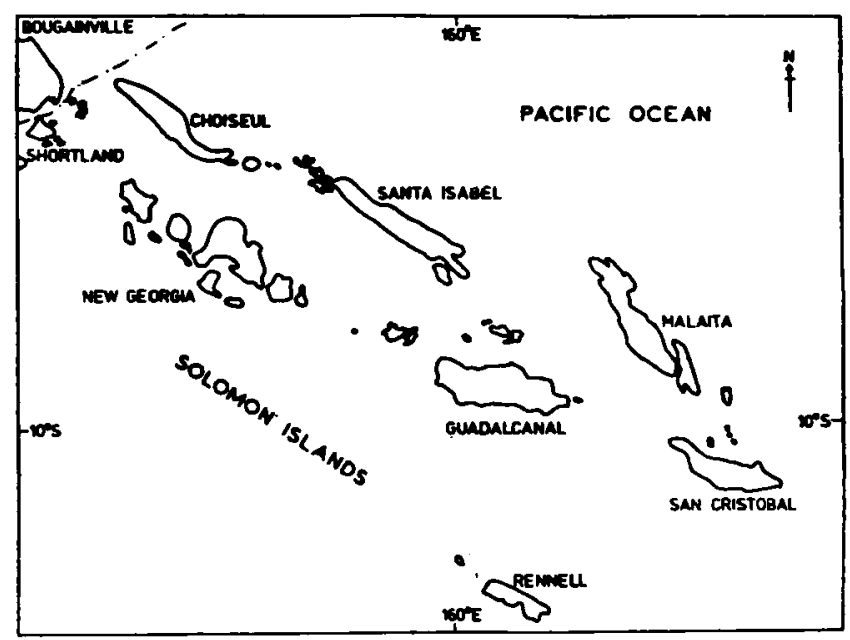

Fig. 1. The Solomon Islands. 


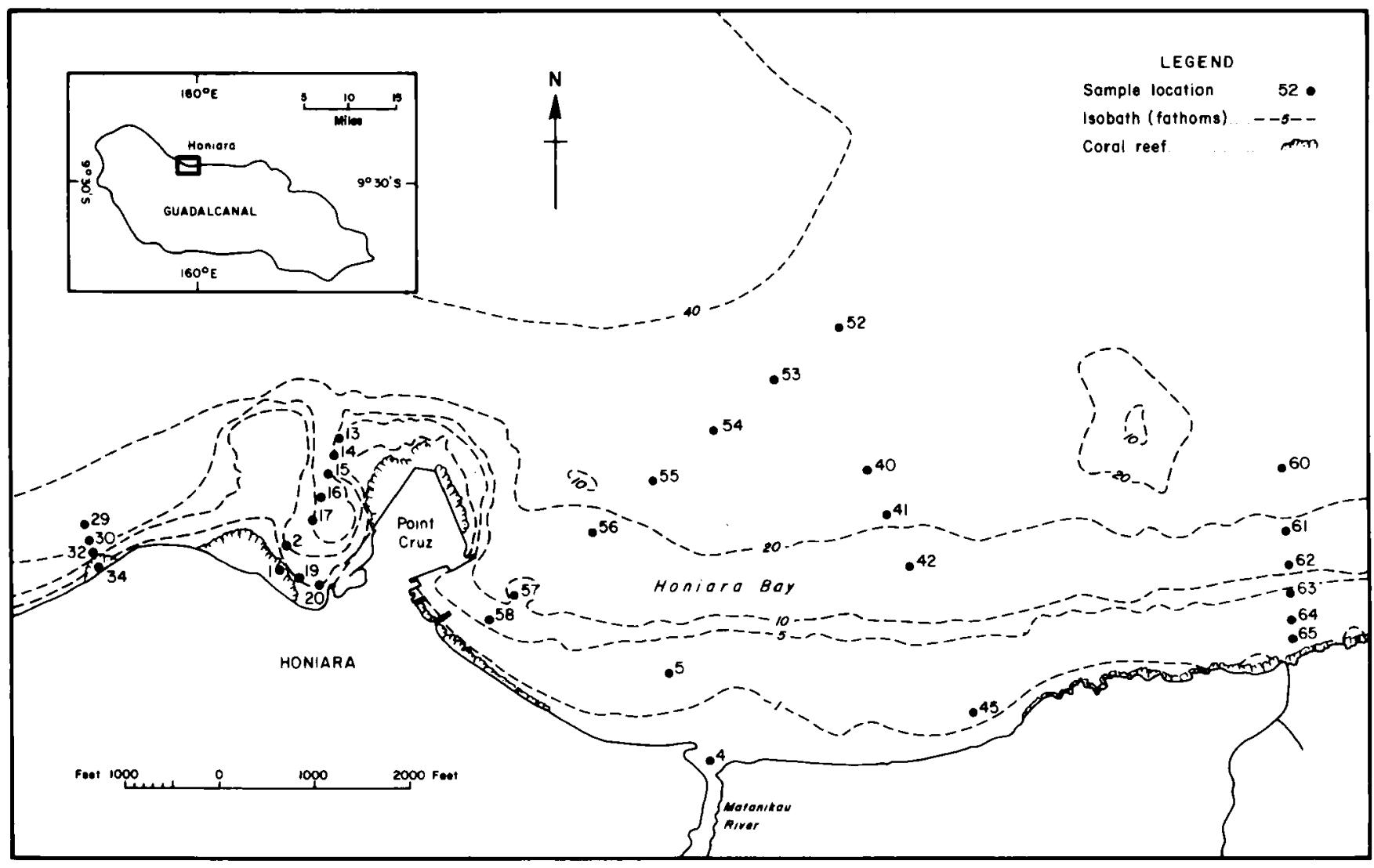

Fig. 2. Location of sample stations, Honiara Bay, N. Guadalcanal, Solomon Islands.

possess characters which are, according to Maddocks, diagnostic of Paranesidea and vice versa. Some species possess characters which have not been previously described in any of these genera.

Maddocks (1969) was aware of the shortcomings of her proposed classification in indicating that both Neonesidea and Paranesidea contained different morphological groups probably worthy of subgeneric status. She recognised at least three species with some characters intermediate between Neonesidea and Paranesidea and also remarked on a degree of convergence between species of Paranesidea and Triebelina.

The general validity of Maddocks classification can be demonstrated in that, with respect of Neonesidea and Paranesidea, most species can be readily accommodated within one or other of the two genera. There remains, however, a persistently difficult group of species which seem to possess an amalgam of the diagnostic characters of both genera. A possible solution to this problem is to more clearly distinguish those characters which are of greatest classificatory value, to employ them and to downgrade characters of lesser significance. This, however, tends to lead to reliance on single characters, such as auxiliary dentition to recognise Bairdoppilata.
Bolz (1971), in his study of the Late Triassic Bairdiidae and Healdiidae considered this problem and concluded that the "previous taxonomic conception" of the Bairdiidae was too often based on a single morphological character. He concluded that many Triassic genera were invalid and advocated an examination and assessment of "all available morphological features of a species in their interrelations and dependencies from each other. By comparing interrelated groups of markers in different species one may really succeed in establishing units in line with the natural system."

In the present study the authors have tried to take into account all available characters in assessing the various taxa encountered with respect to their specific and generic assignments. Certain taxa remain problematical. These are discussed individually below.

Notwithstanding the problems we have encountered, we consider that it is beyond the scope of the intention of this paper and its material, limited as it is by its geographical confines, to attempt a revision of the Bairdiinae at the generic level. 


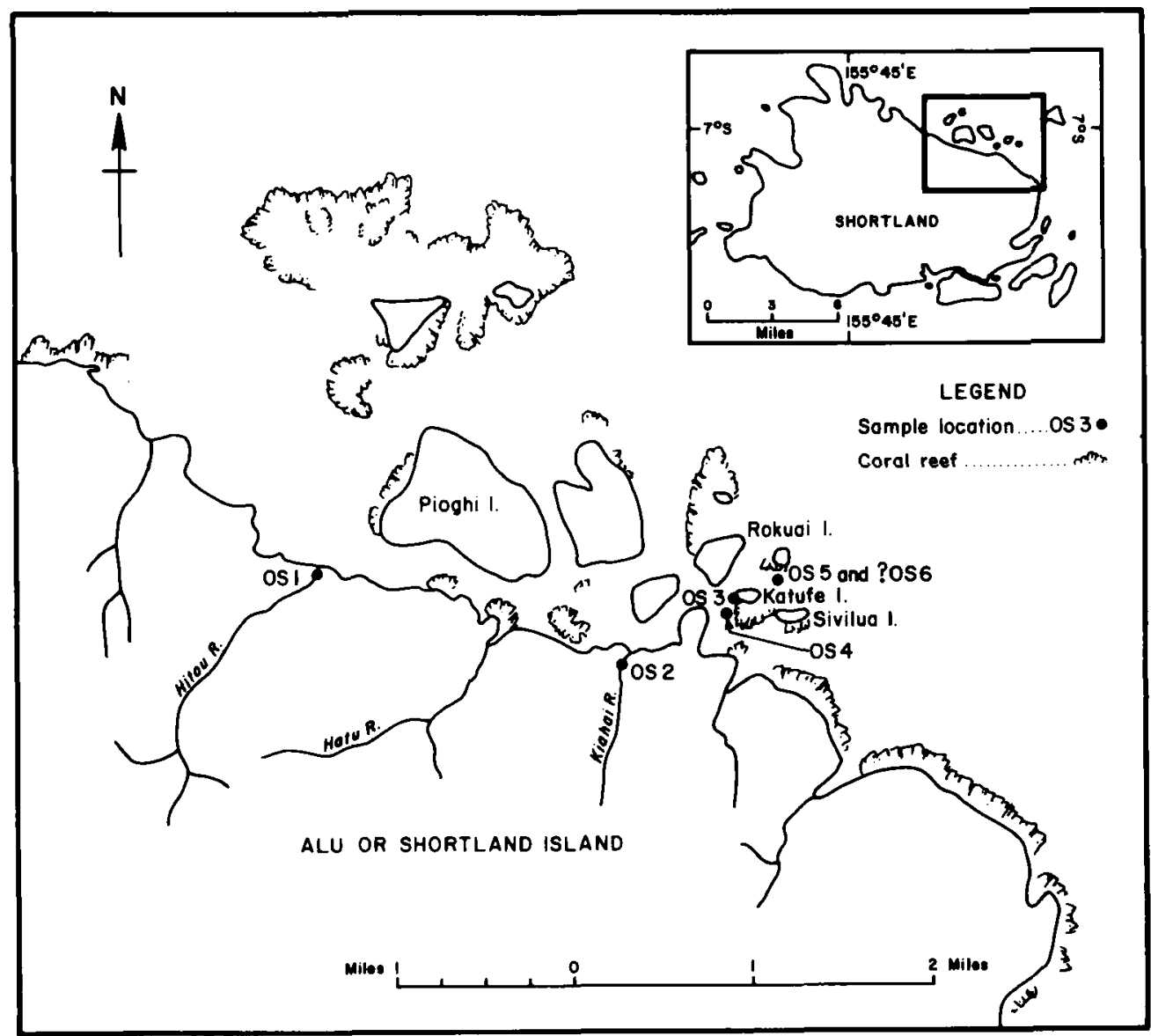

Fig. 3. Location of sample stations, Shortland Island, Solomon Islands.

\begin{tabular}{lll}
\multicolumn{3}{c}{ SYSTEMATIC DESCRIPTIONS } \\
Order & Podocopida & Müller, 1894 \\
Suborder & Podocopina & Sars, 1866 \\
Superfamily & Bairdiacea & Sars, 1888 \\
Family & Bairdiidae & Sars, 1888 \\
Subfamily & Bairdiinae & Sars, 1888 \\
Genus & Bairdoppilata & Coryell, Sample \& \\
& & Jennings, 1935
\end{tabular}

Bairdoppilata paraalcyonicola sp. nov.

(Fig. 5, Nos., 1-2; PI. 1, Figs. 1-8)

Derivation of name. L. From the similarity in overall morphology of this species to B. alcyonicola Maddocks, 1969, from the Recent of Madagascar.

Diagnosis. Bairdoppilate; posterior excavated, slightly upswept. Surface with minute but deep and dense punctae evenly distributed over entire surface. Contact groove of RV with locellae; auxiliary dentition well developed. Small, subcentral, regularly ovate opaque patch and 2 smaller patches at anterodorsal angle and posterior extremity. Narrow, single, vestibule, continuous about anterior, ventral and posterior margins.
Holotype. LV 1986.438.

Material. 37 specimens: 29 adults, 8 juveniles to $\mathrm{A}-3$. Type locality and horizon. Sample 2, 500 feet offshore west of Point Cruz, Honiara Bay, Guadalcanal, Solomon Islands. 1.5 fathoms. Medium coral sand. Recent. Description. Large to very large. Thick-shelled. Translucent with small, subcentral, regularly ovate opaque patch and 2 smaller patches at posterior extremity and anterodorsal angle. Bairdoppilate in lateral view; elliptical in dorsal. Anterior asymmetrically rounded: anterodorsal slope slightly concave; anteroventral slope broadly convex; extremity just above mid-height. Posterior excavated, slightly upswept, extremity below mid-height: posterodorsal slope almost straight, slightly concave near extremity; posteroventral slope convex. Dorsally convex in LV; straight in RV. Cardinal angles rounded in $\mathrm{LV}$; pronounced in RV. Ventral margin biconvex; obscured by lateral inflation in LV. Maximum length just below mid-height in $\mathrm{LV}$, well below mid-height in RV; maximum height median in $L V$, at anterior $1 / 3$ of length in $R V$; maximum width median. Lateral surface densely covered with minute but relatively deep punctae. Internal features typical of 
genus with auxiliary dentition of 4-6 teeth in RV and dorsal contact groove of RV with distinct locellae. Dimensions ( $\mathrm{mm}$ )

\begin{tabular}{rllrrr} 
Holotype & LV & 1986.438 & 2 & 1.00 & 0.67 \\
Paratype & RV & 1986.439 & 2 & 0.99 & 0.55 \\
Paratype & RV & 1986.440 & 15 & 0.93 & 0.51 \\
Paratype & LV & 1986.441 & 1 & 0.94 & 0.59 \\
Paratype & RV & 1986.442 & 2 & 0.94 & 0.52 \\
Paratype & LV & RT/SIR/134 & 16 & 0.95 & 0.61 \\
Mean and range of dimensions (mm) \\
\multicolumn{5}{c}{ length } \\
8 LV & \multicolumn{3}{c}{$0.98(0.90-1.05)$} & $0.63(0.57-0.70)$ \\
16 & RV & & $0.96(0.85-1.04)$ & $0.52(0.43-0.59)$ \\
3 & RV & A-1 & $0.83(0.79-0.87)$ & $0.43(0.41-0.47)$ \\
4 & A-2 & $0.75(0.73-0.78)$ & $0.41(0.38-0.46)$ \\
1 & A-3 & 0.68 & 0.34
\end{tabular}

Remarks. Topotypic material from Maddocks collection from Madagascar, has been examined and compared with the present species. Bairdoppilata alcyonicola is very similar but is smaller and differs in shape, particularly posteriorly being slightly more caudate and the posterior extremity is more dorsal than in the present species. The pattern of the opaque patches (fig. 5 , nos. 1-2) is more simple and well defined in the present species, covering a smaller surface area. Insufficient specimens were available to ascertain sexual dimorphism with certainty, but some right valves were much larger than others; they may represent females. $B$. paraalcyonicola is densely and finely punctate, while $B$. paracratericola sp. nov. is coarsely punctate (more typical of the genus Paranesidea).

Distribution. Samples: 1, 2, 13, 14, 15, 16, 29, 0S5, 0S6, Guadalcanal and Shortland Islands.

Bairdoppilata paracratericola sp. nov.

(Fig. 5, Nos. 3-4; Pl. 1, Figs. 9-16)

Derivation of name. $L$. from the similarity in overall morphology of this species to $B$. cratericola Maddocks, 1969, from the Recent of Madagascar.

Diagnosis. Bairdoppilate; posterior excavated, upswept. Valve surface coarsely puctate; puncta decrease in size peripherally. Contact groove of RV divided lengthwise, smooth dorsally and with fine locellae ventrally; auxiliary dentition well developed. Large opaque patch elliptical, subcentral, irregular in outline. Holotype. LV 1986.443.

Material. 57 specimens: 16 adults, 41 juveniles to A-3. Type locality and horizon. Sample 60,550 feet offshore, east of the Matanikau River, Honiara Bay, Guadalcanal, Solomon Islands. 19 fathoms. Fine coral sand. Recent.

Description. Large. Thick-shelled. Translucent with single, small, elliptical opaque patch subcentrally. Bairdoppilate in lateral view; elliptical in dorsal.
Anterior asymmetrically rounded; anterodorsal slope slightly concave; anteroventral slope broadly convex; apex almost a right angle at mid-height in LV, just above mid-height in RV. Posterior cavolate, upswept, more so in RV, extremity well below mid-height; posterodorsal slope gently convex, concave near extremity; posteroventral slope more convex in LV than RV. Weak marginal frill antero- and posteroventrally in RV and posteroventrally in LV; small, spinose denticles anteroventrally in LV. Dorsally convex in LV; straight and inclined to posterior in RV. Cardinal angles rounded. Ventral margin gently biconvex, RV with pronounced convexity anteroventrally. Maximum length below mid-height in $\mathrm{LV}$, well below mid-height in $R V$; maximum height median in $L V$, at anterior $1 / 3$ of length in RV; maximum width median. Lateral surface covered with large, circular punctae, decreasing in size peripherally, absent around margins, generally concentric about mid-point. Internal features typical of subgenus but RV dorsal contact groove with distinct locellae along ventral half, smooth dorsally.

Dimensions $(\mathrm{mm}) \quad$ sample length height width

$\begin{array}{lllll}\text { Holotype LV } & 1986.443 & 60 & 0.92 & 0.60\end{array}$

$\begin{array}{lllll}\text { Paratype RV } & 1986.444 & 29 & 0.92 & 0.49\end{array}$

$\begin{array}{llllll}\text { Paratype Car. } 1986.445 & 14 & 0.89 & 0.56 & 0.40\end{array}$

$\begin{array}{lllll}\text { Paratype RV } & 1986.446 & 57 & 0.89 & 0.50\end{array}$

$\begin{array}{lllll}\text { Paratype LV } & 1986.447 & 57 & 0.86 & 0.56\end{array}$

$\begin{array}{lllll}\text { Paratype RV } & 1986.448 & 30 & 0.92 & 0.53\end{array}$

$\begin{array}{lllll}\text { Paratype LV } & 1986.449 & 30 & 0.91 & 0.59\end{array}$

\begin{tabular}{rllll}
\multicolumn{2}{c}{ Mean and range of dimensions (mm) } \\
& \multicolumn{1}{c}{$\begin{array}{c}\text { length } \\
\text { height }\end{array}$} & width \\
9 & LV & $0.89(0.78-0.95)$ & $0.58(0.50-0.60)$ & \\
7 & RV & $0.88(0.80-0.92)$ & $0.48(0.42-0.51)$ & \\
1 & Car. A-1 & 0.73 & 0.45 & 0.33 \\
12 & LV A-1 & $0.75(0.71-0.77)$ & $0.46(0.42-0.48)$ & \\
12 & RV A-1 & $0.74(0.69-0.78)$ & $0.41(0.40-0.44)$ & \\
1 & Car. A-2 & 0.59 & $0.32(0.29-0.36)$ & 0.26 \\
11 & A-2 & $0.57(0.55-0.59)$ & $0.33(0.29-0.36)$ \\
4 & A-3 & $0.42(0.41-0.43)$ & $0.25(0.23-0.28)$ &
\end{tabular}

Remarks. Topotypic material from Maddocks collection from Madagascar, has been examined and compared with the present species. Bairdoppilata cratericola differs in shape in that the anterior and posterior extremities are slightly more dorsal. Three adult valves are distinctly smaller and may represent males.

Distribution. Quaternary. Indispensible Reefs, Solomon Islands (Williams, 1980, MS). Samples: 1, 2, 13, $14,15,16,20,29,30,53,54,55,56,57,58,60$, OS6, Guadalcanal and Shortland Islands.

Genus Neonesidea Maddocks, 1969 Neonesidea schulzi (Hartmann, 1964) sensu lato (Fig. 5, Nos. 5-7; Pl. 2, Figs. 1-10) 
Recent Bairdiinae from the Solomon Islands

Table 1. Sample Data

(a) Honiara Bay

\begin{tabular}{|c|c|c|c|c|}
\hline $\begin{array}{l}\text { SAMPLE } \\
\text { NUMBER }\end{array}$ & $\begin{array}{l}\text { WEIGHT } \\
\text { (grammes) }\end{array}$ & $\begin{array}{l}\text { DEPTH } \\
\text { (fathoms) }\end{array}$ & $\begin{array}{l}\text { DISTANCE } \\
\text { OFFSHORE } \\
\text { (feet) }\end{array}$ & $\begin{array}{c}\text { SEDIMENT } \\
\text { (unconsolidated) }\end{array}$ \\
\hline 1 & 105.0 & 1.5 & 200 & Medium coral sand \\
\hline 2 & 101.0 & 1.5 & 500 & Medium coral sand \\
\hline 4 & 171.0 & - & River mouth & Coral sand \\
\hline 5 & 57.4 & 3.0 & 800 & Medium sand \\
\hline 13 & 2.6 & 11.0 & 1,800 & Medium coral sand \\
\hline 14 & 7.6 & 10.0 & 1,400 & Medium coral sand \\
\hline 15 & 12.5 & 13.0 & 1,350 & Medium coral sand \\
\hline 16 & 4.1 & 13.0 & 1,100 & Medium coral sand \\
\hline 17 & 10.8 & 10.0 & 850 & Medium coral sand \\
\hline 19 & 14.1 & 1.5 & 300 & Medium coral sand \\
\hline 20 & 14.9 & 2.0 & 100 & Medium coral sand \\
\hline 29 & 6.3 & 19.0 & 550 & Fine coral sand \\
\hline 30 & 10.9 & 18.0 & 400 & Medium coral sand \\
\hline 32 & 14.5 & 5.0 & 250 & Medium coral sand \\
\hline 34 & 17.1 & 0.5 & 50 & Medium coral sand \\
\hline 40 & 14.7 & 20.0 & 3,100 & Medium sand \\
\hline 41 & 8.7 & 19.0 & 2,600 & Medium sand \\
\hline 42 & 13.6 & 15.0 & 2,000 & Medium sand \\
\hline 45 & 52.3 & 2.0 & 350 & Medium sand \\
\hline 52 & 10.9 & 36.0 & 5,200 & Fine sand \\
\hline 53 & 6.4 & 30.0 & 4,400 & Very fine sand \\
\hline 54 & 7.7 & 24.0 & 3,600 & Very fine sand \\
\hline 55 & 9.8 & 19.0 & 2,700 & Very fine sand \\
\hline 56 & 11.3 & 15.0 & 1,900 & Very fine sand \\
\hline 57 & 9.0 & 8.0 & 850 & Very fine sand \\
\hline 58 & 7.7 & 7.0 & 500 & Very fine sand \\
\hline 60 & 8.3 & 24.0 & 2,000 & Very fine sand \\
\hline 61 & 11.2 & 20.0 & 1,350 & Very fine sand \\
\hline 62 & 20.0 & 6.0 & 1,000 & Fine sand \\
\hline 63 & 23.5 & 5.0 & 700 & Medium sand \\
\hline 64 & 21.2 & 4.0 & 450 & Fine sand \\
\hline 65 & 13.9 & 4.0 & 250 & Very fine sand \\
\hline
\end{tabular}

(b) Shortland Island

\begin{tabular}{ccll}
\hline $\begin{array}{c}\text { SAMPLE } \\
\text { NUMBER }\end{array}$ & $\begin{array}{c}\text { WEIGHT } \\
\text { (grammes) }\end{array}$ & LOCATION & \multicolumn{1}{c}{ SEDIMENT } \\
\hline OS1 & 15.3 & River mouth & Medium sand \\
OS2 & 16.7 & River mouth & Medium sand \\
OS3 & 15.6 & Coral reef & Medium coral sand \\
OS4 & 15.5 & Coral reef & Coarse coral sand \\
OS5 & 509.0 & Coral reef & Coarse coral sand \\
OS6 & 311.0 & Coral reef & Coarse coral sand \\
\hline
\end{tabular}



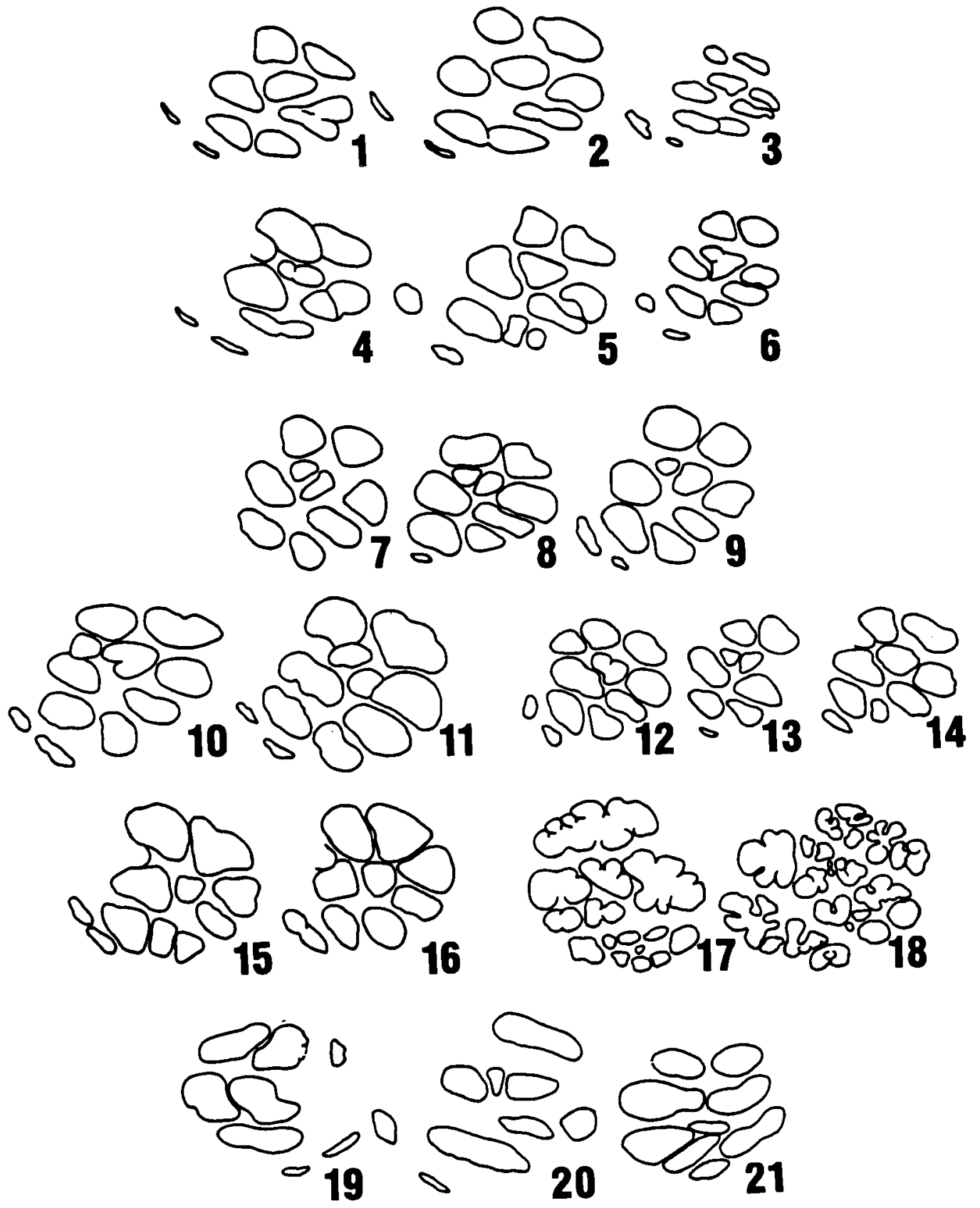

Fig. 4. Muscle Scar patterns (outlines from S.E.M. photographs). 1, Neonesidea schulzi (Hartmann, 1964). RT/SIR/6 RV; 2, Neonesidea vscripta sp. nov. Paratype 1986.459 RV; 3, Neonesidea sp. A. RT/SIR/31 RV; 4, Neonesidea paragierloffi sp. nov. Paratype 1986.453 RV; 5, Neonesidea sp. aff. N. woodwardiana (Brady, 1880), RT/SIR/34 RV; 6, Paranesidea? confusa sp. nov. Paratype 1986.500 RV; 7, Paranesidea stricta sp. nov. Paratype 1986.490; 8, Triebelina bradyi Triebel, 1948, RT/SIR/107 RV; 9, Paranesidea? sp. cf. P. globulus (Brady, 1880), 1986.494 RV; 10, Paranesidea bipustulosa sp. nov. Paratype 1986.473 RV; 11, Paranesidea corbita sp. nov. Paratype 1986.477 RV; 12, Paranesidea equipunctata sp. nov. Paratype 1986.480 RV; 13, Triebelina sertata Triebel, 1948. RT/SIR/133 RV; 14, Paranesidea algicola Maddocks, 1969. RT/SIR/66 RV; 15, Bairdoppilata paraalcyonicola sp. nov. Paratype 1986.442 RV; 16, Bairdoppilata paracractericola sp. nov. Paratype 1986.448 RV; 17, Paranesidea petalona sp. nov. Paratype 1986.485 LV; 18, Neonesidea? sp. B RT/SIR/38 RV; 19, Neonesidea? rara sp. nov. Holotype 1986.466 LV; 20, Neonesidea? crepidula sp. nov. Paratype 1986.463 RV; 21, Pterobairdia briggsae McKenzie, 1986. RT/SIR/137 LV. 

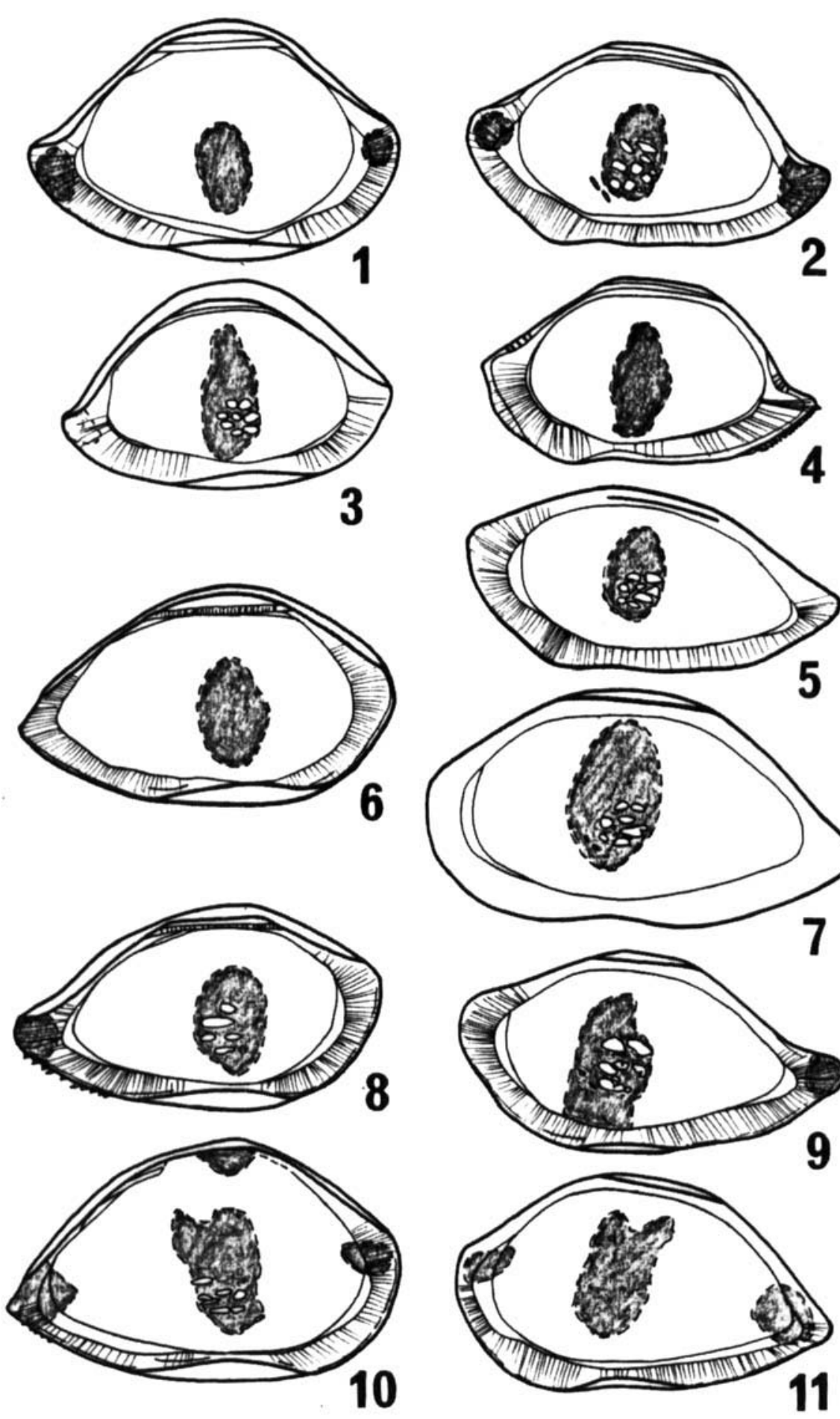

Fig. 5. Bairdoppilata paraalcyonicola sp. nov. 1, Paratype RT/SIR/134 LV, int. lat ( $\times 53) ; 2$, Paratype 1986.442 RV, int. lat. (×52). Bairdoppilata paracratericola sp. nov. 3, Paratype 1986.449 LV, int. lat. ( $\times 49)$; 4, Paratype 1986.446 RV, int. lat. $(\times 52)$. Neonesidea schulzi (Hartmann, 1964). 5, RT/SIR/11 LV, LV, int. lat. $(\times 55) ; 6$, RT/SIR/10 RV, int. lat. $(\times 53) ; 7, \mathrm{RT} / \mathrm{SIR} / 9 \mathrm{RV}$, int. lat. $(\times 52)$. Neonesidea paragierloffi sp. nov. 8, Paratype RT/SIR/20 LV, int. lat. $(\times 50) ; 9$, Paratype RT/SIR/21 RV, int. lat. $(\times 53)$. Neonesidea vscripta sp. nov. 10, Paratype RT/SIR/30 LV, int. lat. $(\times 55) ; 11$, Paratype RT/SIR/29 RV, int. lat. $(\times 51)$. 
1964 Triebelina schulzi sp. nov. Hartmann: 44, figs. 14-22; pls. 4-5.

1966 Species BA Maddocks: 47, fig. 22.

1969 Neonesidea schulzi (Hartmann); Maddocks: 20 , figs. $4 a-d, 5-6$.

?1976 Neonesidea schulzi (Hartmann); Holden: 12, pl. 7, figs. 9-11.

1976 Neonesidea schulzi (Hartmann): Bonaduce et al.: 376 , pl. 4 , fig. 6 .

Material. Over 700 specimens, adults and juveniles to A-4.

Mean and range of dimensions $(\mathrm{mm})$ length
10 LV (large)
$1.03(0.95-1.19)$
$1.00(0.95-1.02)$
$0.87(0.78-0.92)$
$0.89(0.81-0.94)$
$0.61(0.55-0.68)$
$0.56(0.51-0.59)$
$0.51(0.44-0.54)$
$0.46(0.41-0.51)$
$10 \mathrm{RV}$ (small)

height

Remarks. This species in its shape, surface ornament, marginal denticulation and internal characters is characteristic of the genus Neonesidea. It may be distinguished initially by its single, elliptical central opaque patch.

There is a great variation in size in the adults and $\mathrm{A}-1$ juveniles in the present material; some $\mathrm{A}-1$ instars are larger than the smallest adults; although there is a continual range in size. Details can be seen in Titterton (1984, MS). This variation in size indicates the probable presence of more than one species or subspecies. The lack of soft parts and distinctive size clusters precludes accurate and consistent identification of these very closely related species. All specimens at present are, therefore, placed in $N$. schulzi. A study being conducted by $K$. Watson (in press) on the ostracod faunas from reefal environments in the Java Sea, has allowed this problem to be more satisfactorily resolved, due to the availability of more bairdiid material. Watson (verb. comm., 1987) discriminates two further new species within the $N$. schulzi plexus sensu this work.

Distribution. Miocene, Midway Island (Holden, 1976). Quaternary, Indispensible Reefs, Solomon Islands (Williams, 1980, MS). Recent, shallow water and littoral sediments along the eastern coast of Africa, around Madagascar, the Red Sea and Gulf of Aqaba (Hartmann, 1964, 1974; Maddocks, 1966, 1969; Bonaduce et al., 1976).

Samples: 1, 2, 5, 13, 14, 15, 16, 17, 20, 29, 30, 32, 40, $41,53,54,55,56,57,58$, OS4, OS5, OS6, Guadalcanal and Shortland Islands.

Neonesidea paragierloffi sp. nov.

(Fig. 5, Nos. 8-9; Pl. 3, Figs. 1-10)

Derivation of name. L. From the similarity in overall morphology of this species to $N$. gierloffi Hartmann, 1959, from the Recent of El Salvador.

Diagnosis. Typical Neonesidea in shape; posterodorsal slope straight, becoming strongly concave near posterior; posteroventral slope with 12 triangular marginal denticles in LV only. Valve surface with dense minute, punctae, translucent with large, oval central opaque patch and two small patches at posterior extremity and anterodorsal angle.

Holotype. LV 1986.450.

Material. 132 specimens: 45 adults, 87 juveniles to A-4.

Type locality and horizon. Sample 14, 1,400 feet offshore west of Point Cruz, Honiara Bay, Guadalcanal, Solomon Islands. 10 fathoms. Medium coral sand. Recent.

Description. Large to very large. Moderately thinshelled. Translucent with central oval opaque patch and two smaller patches at posterior extremity and anterodorsal angle. Shape typical of genus in lateral and dorsal views. Anterior asymmetrically rounded: anterodorsal slope gently concave; anteroventral slope broadly convex; apex a pronounced right angle above mid-height. Posterior slightly upswept, acuminate, extremity at mid-height in LV, below in RV, posterodorsal slope straight becoming strongly concave towards extremity; posteroventral slope convex with 12 small, triangular marginal denticles in LV only. Dorsally convex in LV; straight in RV. Cardinal angles rounded in LV; pronounced in RV. Ventral margin gently convex in LV, biconvex in RV. Maximum length

\section{Explanation of Plate 1}

Figs. 1-8. Bairdoppilata paraalcyonicola sp. nov.: fig. 1, Holotype $1986.438 \mathrm{LV}$, ext. lat. (× 45); fig. 2, Paratype 1986.439 RV, ext. lat. ( $\times 45)$; fig. 3, Paratype 1986.441 LV, int. lat. ( $\times 49)$; fig. 4, Paratype 1986.440 RV, int. lat. ( $\times 47)$; fig. 5, Paratype 1986.442 RV, detail of central muscle scars $(\times 160)$; fig. 6, Paratype 1986.441 LV, detail of hinge $(\times 95)$; fig. 7, Paratype $1986.440 \mathrm{RV}$, detail of hinge $(\times 92)$; fig. 8, Paratype $1986.440 \mathrm{RV}$, detail of hinge $(\times 450)$.

Figs. 9-16. Bairdoppilata paracratericola sp. nov.: fig. 9, Paratype $1986.448 \mathrm{RV}$, detail of central muscle scars ( $\times 205)$; fig. 10, Holotype $1986.443 \mathrm{LV}$; ext. lat. ( $\times 44)$; fig. 11, Paratype $1986.444 \mathrm{RV}$, ext. lat. $(\times 44)$; fig. 12, Holotype 1986.443 LV, detail of hinge $(\times 63)$; fig. 13 , Holotype $1986.443 \mathrm{LV}$, int. lat. $(\times 47)$; fig. 14, Paratype 1986.446 RV, int. lat. $(\times 48)$; fig. 15 , Holotype $1986.443 \mathrm{LV}$, detail of hinge $(\times 420)$; fig. 16, Paratype 1986.446 RV, detail of hinge $(\times 94)$. 


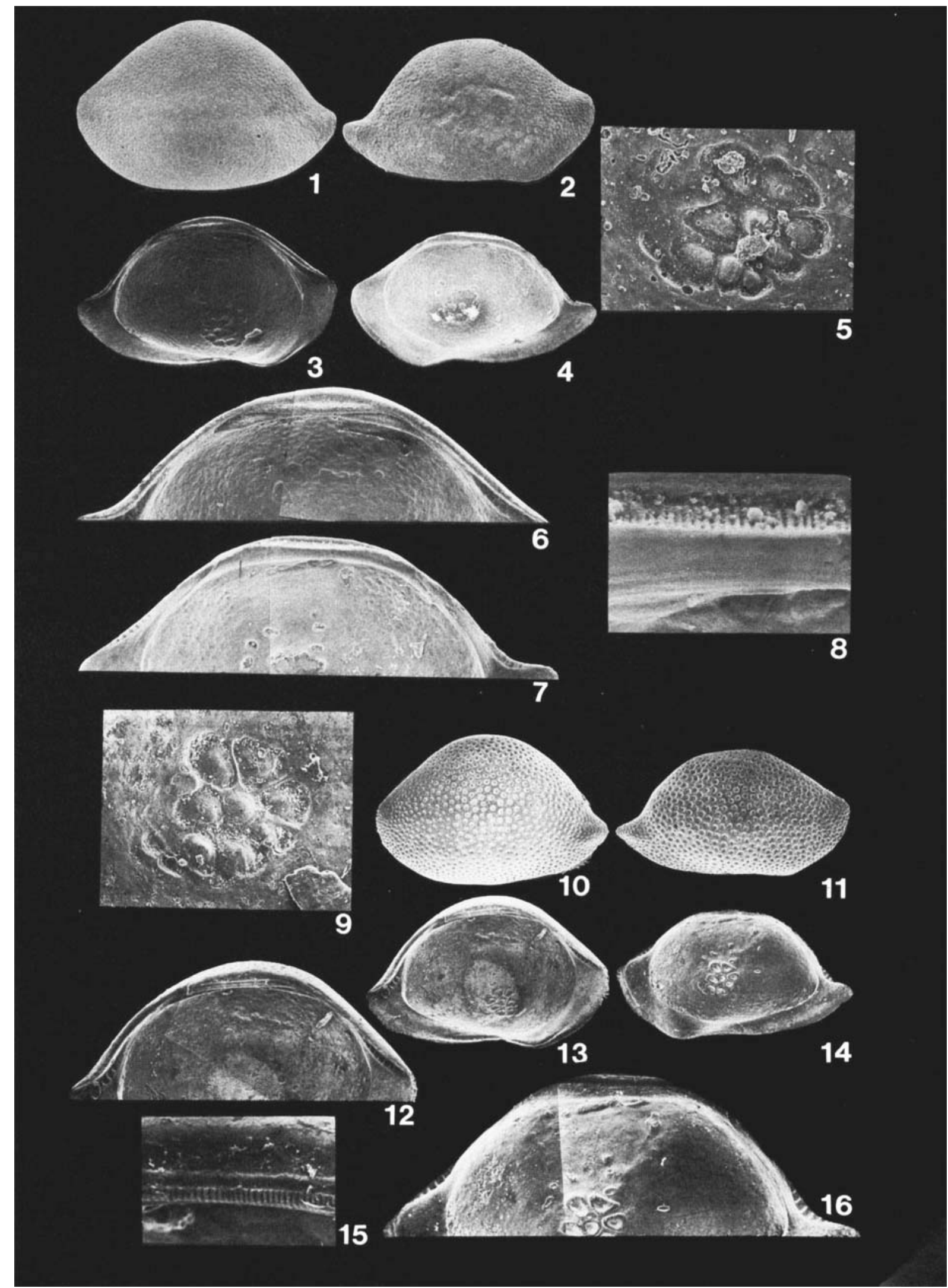


mid-height in LV, below mid-height in RV; maximum height median in $L V$, at anterior $1 / 3$ of length in $R V$; maximum width at anterior $1 / 3$ of length. Lateral surface covered with dense minute punctae. Internal characters typical of genus.

Dimensions (mm)

$\begin{array}{llrrrr}\text { Holotype LV } & 1986.450 & 14 & 1.01 & 0.64 & \\ \text { Paratype Car. } & 1986.451 & 13 & 1.01 & 0.58 & 0.46 \\ \text { Paratype RV } & 1986.452 & 15 & 1.03 & 0.55 & \\ \text { Paratype RV } & 1986.453 & 1 & 1.02 & 0.55 & \\ \text { Paratype LV } & 1986.454 & 14 & 0.95 & 0.54 & \\ \text { Paratype RV } & \text { RT/SIR/18 } & 1 & 1.00 & 0.54 & \\ \text { Paratype LV } & \text { RT/SIR/19 } & 14 & 1.02 & 0.61 & \\ \text { Paratype LV } & \text { RT/SIR/20 } & 15 & 1.00 & 0.57 & \\ \text { Paratype RV } & \text { RT/SIR/21 } & 1 & 0.98 & 0.54 & \end{array}$

$\begin{array}{rcc}\text { Mean and range of dimensions (mm) } \\ & \begin{array}{c}\text { length } \\ \text { height }\end{array} \\ \text { 8 LV (large) } & 1.06(1.02-1.13) & 0.58(0.57-0.64) \\ 11 \text { RV (large) } & 1.02(0.99-1.09) & 0.63(0.59-0.70) \\ 8 \text { LV (small) } & 0.98(0.95-1.00) & 0.56(0.54-0.60) \\ 9 \text { RV (small) } & 0.98(0.91-1.04) & 0.53(0.50-0.56) \\ \text { 20 LV A-1 } & 0.83(0.78-0.92) & 0.49(0.44-0.53) \\ 11 \text { RV A-1 } & 0.82(0.77-0.89) & 0.46(0.42-0.48) \\ \text { 22 A-2 } & 0.62(0.54-0.70) & 0.35(0.31-0.37) \\ 18 \text { A-3 } & 0.46(0.40-0.52) & 0.26(0.20-0.30) \\ 6 \text { A-4 } & 0.34(0.32-0.35) & 0.19(0.18-0.20)\end{array}$

Remarks. This species differs from the $N$. schulzi in that the posterior is upswept so that the posterodorsal slope is concave. This feature, and the consistent presence of anterior and posterior opaque patches, distinguish it from $N$. schulzi to which it is most similar among the present material. It most closely resembles N. gierloffi (Hartmann, 1959) from Recent sediments from El Salvador in shape, but differs in that the caudal process is more upturned.

Like $N$. schulzi and $N$. vscripta in the present material, $N$. paragierloff $i$ is very variable in size with a difference of over $0.20 \mathrm{~mm}$ in length between the largest and smallest adults.

Distribution. Samples: 1, 2, 5, 13, 14, 15, 16, 17, 19, $29,30,45,53,55,56,57,58$, Guadalcanal.
Neonesidea vscripta sp. nov.

(Fig. 5, Nos. 10-11; PI. 2, Figs. 11-19)

Derivation of name. $\mathrm{L}$. With reference to the $v$-shaped central opaque patch.

Diagnosis. Typical Neonesidea in shape; dorsal margin asymmetrically convex towards anterior. Valve surface with dense, minute punctae. Translucent with large, $v$-shaped central opaque patch with two small oval patches at anterodorsal angle and posterior extremity. Holotype. LV 1986.455.

Material. 59 specimens: 37 adults and 22 juveniles to A-2.

Type locality and horizon. Sample 14, 1,400 feet offshore west of Point Cruz, Honiara Bay, Guadalcanal, Solomon Islands. 10 fathoms. Medium coral sand. Description. Large to very large. Moderately thinshelled. Translucent with large $\mathbf{v}$-shaped central opaque patch and two small oval patches at anterodorsal angle and posterior extremity. Shape typical of genus in lateral and dorsal views. Anterior asymmetrically rounded; anterodorsal slope almost straight, anteroventral slope convex; apex above mid-height. Posterior acuminate, extremity well below mid-height; posterodorsal slope straight, posteroventral slope convex. Dorsally asymmetrically convex towards anterior in LV; straight in RV. Cardinal angles rounded in LV; pronounced in RV. Ventral margin gently convex in LV; biconvex in RV. Maximum length below midheight; maximum height median in $\mathrm{LV}$, at anterior $1 / 3$ of length in RV; maximum width just anterior of mid-length. Lateral surface densely covered with minute punctae. Internal features typical of genus.

Dimensions (mm)

$\begin{array}{llrrrr}\text { Holotype LV } & 1986.455 & 14 & 1.04 & 0.69 & \\ \text { Paratype Car. } & 1986.456 & 16 & 0.99 & 0.62 & 0.54 \\ \text { Paratype RV } & 1986.457 & 16 & 1.01 & 0.59 & \\ \text { Paratype LV } & 1986.458 & 15 & 1.05 & 0.68 & \\ \text { Paratype RV } & 1986.459 & 14 & 0.97 & 0.53 & \\ \text { Paratype RV } & \text { RT/SIR/27 } & 15 & 1.04 & 0.62 & \\ \text { Paratype LV } & \text { RT/SIR/28 } & 14 & 1.02 & 0.69 & \\ \text { Paratype RV } & \text { RT/SIR/29 } & 2 & 1.00 & 0.61 & \\ \text { Paratype LV } & \text { RT/SIR/30 } & 2 & 0.97 & 0.60 & \end{array}$

\section{Explanation of Plate 2}

Figs. 1-10. Neonesidea schulzi (Hartmann): fig. 1, RT/SIR/3 LV, ext. lat. $(\times 40)$; fig. 2 , RT/SIR/2 RV, ext. lat. ( $\times 39)$; fig. 3, RT/SIR/5 LV, int. lat. ( $\times 38)$; fig. 4, RT/SIR/1, Car, ext. dorsal $(\times 42)$; fig. 5, RT/SIR/6 RV, int. lat. $(\times 42)$; fig. 6, RT/SIR/6 RV, detail of hinge $(\times 493)$; fig. 7, RT/SIR/4 A-1 LV, ext. lat. $(\times 55)$; fig. 8 , RT/SIR/6 RV, detail of hinge $(\times 90)$; fig. 9, RT/SIR/5 LV, detail of hinge $(\times 76)$; fig. 10, RT/SIR/7 RV, detail of central muscle scars $(\times 220)$.

Figs. 11-19. Neonesidea vscripta sp. nov.: fig. 1, Holotype 1986.455 LV, ext. lat. ( $\times 42)$; fig. 12, Paratype 1986.457 RV, ext. lat. ( $\times 44)$; fig. 13, Paratype $1986.458 \mathrm{LV}$, int. lat. $(\times 43)$; fig. 14, Paratype 1986.456 Car, ext. dorsal $(\times 50)$; fig. 15, Paratype $1986.459 \mathrm{RV}$, int. lat. $(\times 44)$; fig. 16, Paratype $1986.458 \mathrm{LV}$, detail of hinge $(\times 525)$; fig. 17, Paratype 1986.459 RV, detail of hinge $(\times 104)$; fig. 18, Paratype $1986.458 \mathrm{LV}$, detail of central muscle scars (×166); fig. 19, Paratype $1986.458 \mathrm{LV}$, details of hinge $(\times 86)$. 


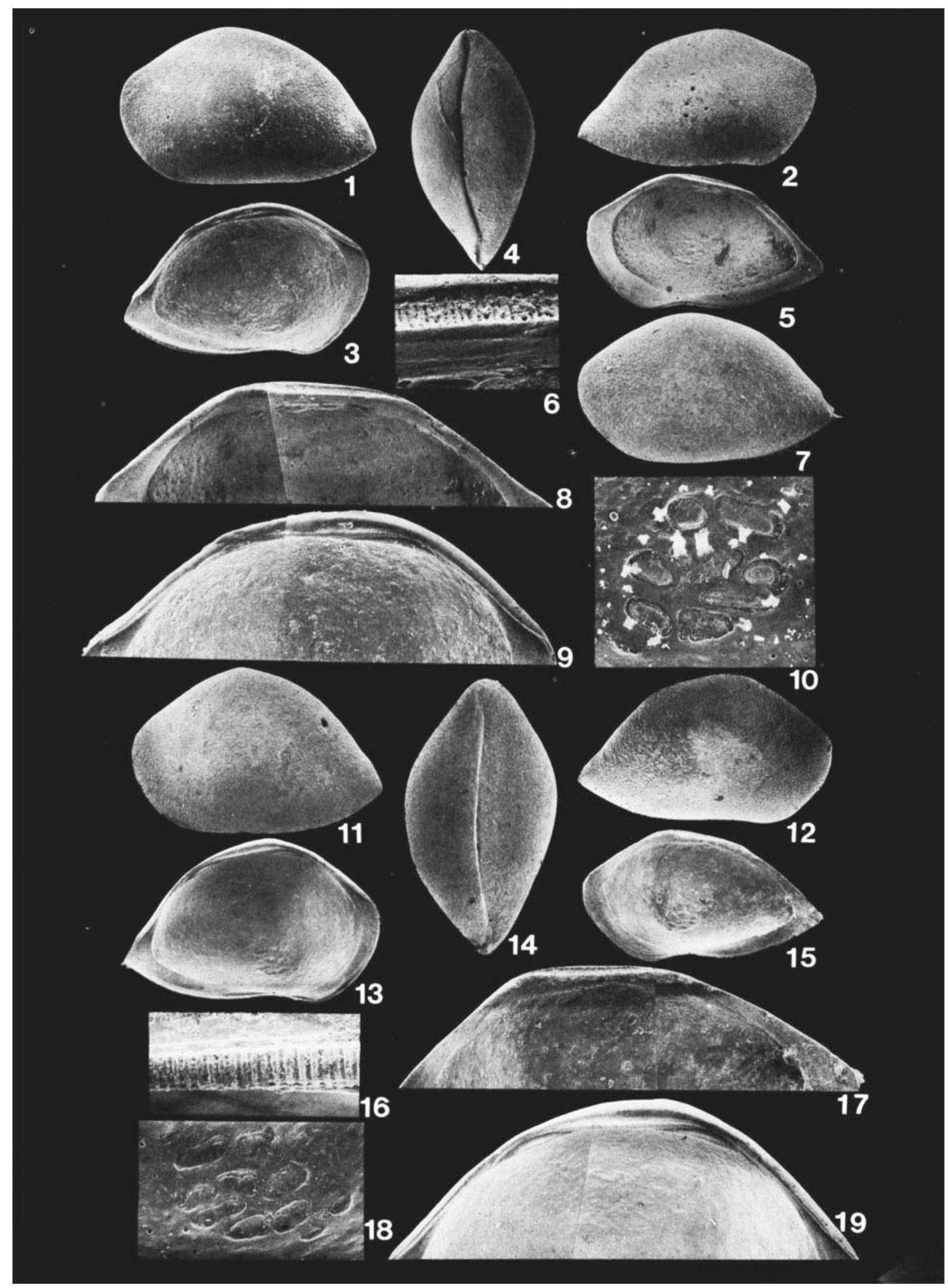


Mean and range of dimensions $(\mathrm{mm})$

$\begin{array}{llcc} & \text { length } & \text { height } & \text { width } \\ 2 \text { Car. } & 0.99,1.00 & 0.62,0.63 & 0.52,0.54\end{array}$

$14 \mathrm{LV} \quad 1.00(0.89-1.08) 0.62(0.53-0.69)$

$12 \mathrm{RV} \quad 0.99(0.92-1.04) 0.56(0.51-0.62)$

10 LV A-1 $0.79(0.76-0.83) 0.49(0.47-0.50)$

9 RV A-1 $0.78(0.74-0.80) 0.45(0.42-0.46)$

2 LV A-2 $0.55,0.57 \quad 0.33,0.34$

Remarks. This species possesses a unique v-shaped central opaque patch. Although $N$. vscripta, like $N$. schulzi, has the characteristic shape of the genus, detailed analysis of their outlines show $N$. vscripta to be relatively higher dorsally, less tapering posteriorly, lacking a posterior spine in the LV and the dorsal margin is asymmetrically convex so that the posterodorsal slope is less convex towards the posterior extremity. Neonesidea kauaienensis Holden, 1967 from the Neogene to Recent of Hawaii, is similar in shape but is about $0.6 \mathrm{~mm}$ longer, possesses a different muscle scar pattern and wider vestibulae.

The adults show a similar range in size as $N$. schulzi and $N$. paragierloffi in the present material.

Distribution. Quaternary, Indispensible Reefs and offshore Guadalcanal, Solomon Islands (Williams, 1980, MS).

Samples: 1, 2, 14, 15, 16, 17, 30, 56, OS5, OS6, Guadalcanal and Shortland Islands.

\section{Neonesidea sp. A}

(Fig. 6, Nos. 1-2; Pl. 3, Figs. 11-18)

Material. Three specimens.

Dimensions (mm)

$\begin{array}{lccc} & \text { sample } & \text { length } & \text { height } \\ \text { RV RT/SIR/31 } & 29 & 1.13 & 0.63 \\ \text { LV RT/SIR/32 } & 19 & 1.11 & 0.70 \\ \text { LV RT/SIR/33 } & 13 & 0.99 & 0.63\end{array}$

Remarks. Although these three specimens are almost identical to $N$. paragierloffi sp. nov., they differ in possessing a large, distinctive vesibule which is continuous around the anterior, ventral and posterior margins.

Distribution. Samples: 13, 19, 29, Guadalcanal.
Neonesidea? sp. aff. Neonesidea woodwardiana (Brady, 1880)

(Fig. 6, Nos. 8-9; Pl. 4, Figs. 1-6)

1880 Bairdia woodwardiana sp. nov. Brady: 57, pl. 11, figs. 1a-e.

Material. 18 specimens: 4 adults, 14 juveniles to $\mathrm{A}-3$. Dimensions (mm)

$\begin{array}{llrcr} & \text { sample } & \text { length } & \text { heigh } \\ \text { LV } & \text { RT/SIR/35 } & \text { OS3 } & 0.76 & 0.39 \\ \text { RV } & \text { RT/SIR/34 } & 1 & 0.77 & 0.37 \\ \text { LV } & \text { RT/SIR/36 } & \text { OS6 } & 0.74 & 0.38 \\ \text { LV } & \text { RT/SIR/37 } & 15 & 0.76 & 0.39\end{array}$

Remarks. This species is tentatively assigned to Neonesidea because the finely punctate surface ornament, its muscle scar pattern and smooth hinge are typical of the genus. However, its elongate, subrectangular shape is not typical. In addition, the antero- and posteroventral margins in the LV bear spinose marginal denticles. The present material has been compared with S.E.M. photographs of the type specimens of $N$. woodwardiana which is very similar in shape but is $0.2 \mathrm{~mm}$ longer and possesses 4 wedge-shaped scars, whereas the present species has a rosette pattern of 8 wedge-shaped scars encircling a central scar. In addition, $N$. woodwardiana possesses opaque patches (illustrated by Puri \& Hulings, 1976); the present species does not.

Distribution. ?Quaternary, off Guadalcanal, Solomon Islands (Williams, 1980, MS). Samples: 1, 2, 14, 15, 16, $17,55,57$, OS3, OS6, Guadalcanal and Shortland Islands.

Neonesidea? crepidula sp. nov.

(Fig. 6, Nos. 5-6; Pl. 4, Figs. 7-13)

Derivation of name. L. With reference to the shape of this species which resembles a medieval shoe.

Diagnosis. Shape subtrapezoidal in lateral view; broadly elliptical in dorsal view, maximum width median. Posterior strongly acuminate, extremity ventral. 12 small, triangular marginal denticles posteroventrally. Valve surface with dense, minute, punctae.

\section{Explanation of Plate 3}

Figs. 1-10. Neonesidea paragierloffi sp. nov.: fig. 1, Holotype $1986.450 \mathrm{LV}$, ext. lat. $(\times 42)$; fig. 2, Paratype 1986.452 RV, ext. lat. (×45); fig. 3, Paratype 1986.454 LV, int. lat. $(\times 47)$; fig. 4, Paratype 1986.451 Car, ext. dorsal $(\times 42)$; fig. 5, Paratype 1986.451 Car, detail of posterior spine $(\times 220)$; fig. 6, Paratype 1986.453 RV, int. lat. ( $\times 43)$; fig. 7, Paratype $1986.453 \mathrm{RV}$, detail of hinge $(\times 89)$; fig. 8, Paratype $1986.453 \mathrm{RV}$, detail of central muscle scars $(\times 266)$; fig. 9, Paratype $1986.454 \mathrm{LV}$, detail of hinge $(\times 90)$; fig. 10, Paratype $1986.454 \mathrm{LV}$, details of hinge $(\times 515)$.

Figs. 11-18. Neonesidea sp. A: fig. 11, RT/SIR/32 LV, ext. lat. $(\times 40)$; fig. 12, RT/SIR/31 RV, ext. lat. $(\times 42)$; fig. 13, RT/SIR/33 LV, ext. lat. ( $\times 41)$; fig. 14, RT/SIR/31 RV, int. lat. $(\times 34)$; fig. $15, \mathrm{RT} / \mathrm{SIR} / 31 \mathrm{RV}$, detail of central muscle scars $(\times 155)$; fig. 16, RT/SIR/33 LV, int. lat. $(\times 45)$; fig. 17, RT/SIR/31 RV, detail of hinge $(\times 81)$; fig. $18, \mathrm{RT} / \mathrm{SIR} / 33 \mathrm{LV}$, detail of hinge $(\times 90)$. 


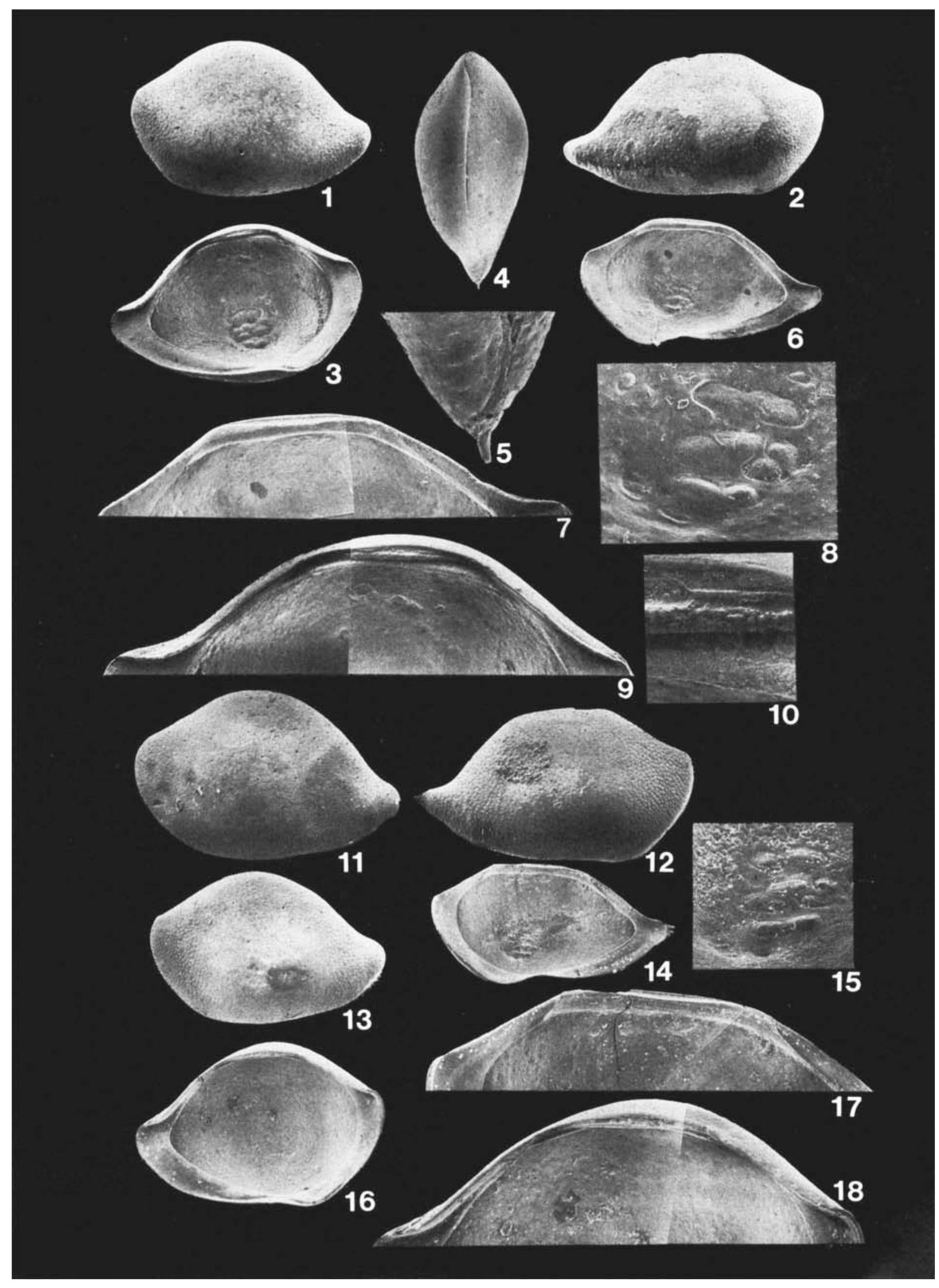


Selvage forms a small notch at posterior extremity in RV. Central muscle scars variable, may be fused, $6-8$ arranged in 3 horizontal rows.

Holotype. LV 1986.460.

Material. 11 specimens: 6 adults, 5 juveniles to A-2. Type locality and horizon. Sample 1, 200 feet offshore west of Point Cruz, Haniara Bay, Guadalcanal, Solomon Islands. 1.5 fathoms. Medium coral sand. Recent. Description. Large. Moderately thick-shelled. Translucent with indistinct, oval, opaque patch subcentrally. Shape subtrapezoidal in lateral view; broadly elliptical in dorsal view. Anterior asymmetrically rounded: anterodorsal and anteroventral slopes almost straight, apex a rounded right angle above mid-height. Posterior strongly acuminate; posterodorsal slope long, straight, becoming concave near ventral extremity. Dorsal margin convex in LV; short, straight in RV; cardinal angles rounded. Ventral margin almost straight; oral concavity more pronounced in RV. 12 small, triangular, marginal denticles posteroventrally in RV. Maximum length subventral; maximum height median in $\mathrm{LV}$, at anterior $1 / 3$ of length in $R V$, maximum width median. Surface of valves with dense minute, punctae. Internal features typical of Neonesidea except unusual, variable muscle scar pattern comprising a loose ovate cluster of 6-8 wedge-shaped scars in 3 horizontal rows; 2 dorsal and 2 ventral scars may be fused into an elongate scar. Dimensions (mm)

$\begin{array}{llrlll}\text { Holotype LV } & 1986.460 & 1 & 0.84 & 0.50 & \\ \text { Paratype Car. } & 1986.461 & 14 & 0.82 & 0.50 & 0.54 \\ \text { Paratype RV } & 1986.462 & \text { OS6 } & 0.84 & 0.46 & \\ \text { Paratype RV } & 1986.463 & 1 & 0.84 & 0.47 & \\ \text { Paratype LV } & 1986.464 & 15 & 0.89 & 0.51 & \\ \text { Paratype LV } & 1986.465 & 15 & 0.89 & 0.54 & \end{array}$

Remarks. The shape of this species is unusual in that the posterior extremity is ventral and the valves are strongly inflated medianly. Although the species is typical of Neonesidea in many features, particularly its surface ornament, its shape is not; the central muscle scar is also unusual. Neonesidea dinochelata (Kornicker, 1961) from Recent sediments from Bimini is most similar in shape, in possessing a posterior selvage notch and variable muscle scar, but differs in that the dorsal margin is longer and more inclined posteriorly and the hinge is weaker.

The tendency for the dorsal and ventral scars to form single scars and the inflated, smooth carapace indicate a relationship with Aponesidea Maddocks, 1986 (Recent, Bermuda). The present species differs from $A$. iliffei, the only species described, in that the maximum width of the carapace is median, and not at a quarter of the height; it possesses a central opaque patch and it lacks marginal denticles in the left valve with only very small, marginal denticles posteroventrally in the right valve and not a marginal frill. Until the full scope of the genus Aponesidea can be established, the present species has been questionably assigned to Neonesidea. Distribution. Samples: 1, 13, 14, 15, OS6, Guadalcanal and Shortland Islands.

Neonesidea? rara $\mathrm{sp}$. nov.

(Fig. 6, Nos. 7, 10; P1. 5, Figs. 10-14)

Derivation of name. L. With reference to the rarity of this species in the present material.

Diagnosis. Medium. Shape subtrapezoidal in lateral view, anteroventral margin broadly convex, dorsal margin weakly convex; almost straight posterior and ventral margins meet at a ventral caudal process. Central muscle scars in 3 horizontal rows, 2 dorsal, 2 median and 1 ventral scar; scars fused.

Holotype. LV 1986.466.

Material. 18 specimens: 6 adults, 12 juveniles to $A-3$. Type locality and horizon. Sample 15, 1,350 feet offshore west of Point Cruz, Honiara Bay, Guadalcanal, Solomon Islands. 13 fathoms. Medium coral sand. Recent.

Description. Medium. Moderately thin-shelled. Translucent. Shape subtrapezoidal in lateral view. Anterior asymmetrically rounded; a short anterodorsal slope merges with dorsal margin; a broadly convex anteroventral slope; apex rounded, well above midheight. Posterior acuminate ventrally so posteroventral

\section{Explanation of Plate 4}

Figs. 1-6. Neonesidea? sp. aff. Neonesidea woodwardiana (Brady): fig. 1, RT/SIR/36 LV, ext. lat. ( $\times 62)$; fig. 2 , RT/SIR/34 RV, ext. lat. $(\times 61)$; fig. 3, RT/SIR/35 LV, int. lat. $(\times 61)$; fig. 4, RT/SIR/34 RV, int. lat. $(\times 54)$; fig. 5 , RT/SIR/35 LV, detail of central muscle scars $(\times 213)$; fig. $6, \mathrm{RT} / \mathrm{SIR} / 35 \mathrm{LV}$, detail of hinge $(\times 119)$.

Figs. 7-13. Neonesidea? crepidula sp. nov. : fig. 7, Holotype 1986.460 LV, ext. lat. $(\times 51)$; fig. 8, Paratype 1986.462 RV, ext. lat. $(\times 66)$; fig. 9 , Holotype $1986.460 \mathrm{LV}$, int. lat. $(\times 49)$; fig. 10, Paratype $1986.461 \mathrm{Car}$, ext. dorsal ( $\times 61)$; fig. 11, Paratype $1986.463 \mathrm{RV}$, int. lat. $(\times 51)$; fig. 12, Paratype $1986.464 \mathrm{LV}$, detail of central muscle scars $(\times 251)$; fig. 13, Paratype $1986.463 \mathrm{RV}$, detail of hinge $(\times 101)$.

Figs. 14-17. Neonesidea? sp. B: fig. 14 , RT/SIR/38 RV, int. lat. $(\times 57)$; fig. 15 , RT/SIR/40 RV, ext. lat. $(\times 64)$; fig. $16, \mathrm{RT} / \mathrm{SIR} / 38 \mathrm{RV}$, detail of hinge and central muscle scars $(\times 113)$; fig. 17, RT/SIR/39 RV, detail of central muscle scars $(\times 236)$. 


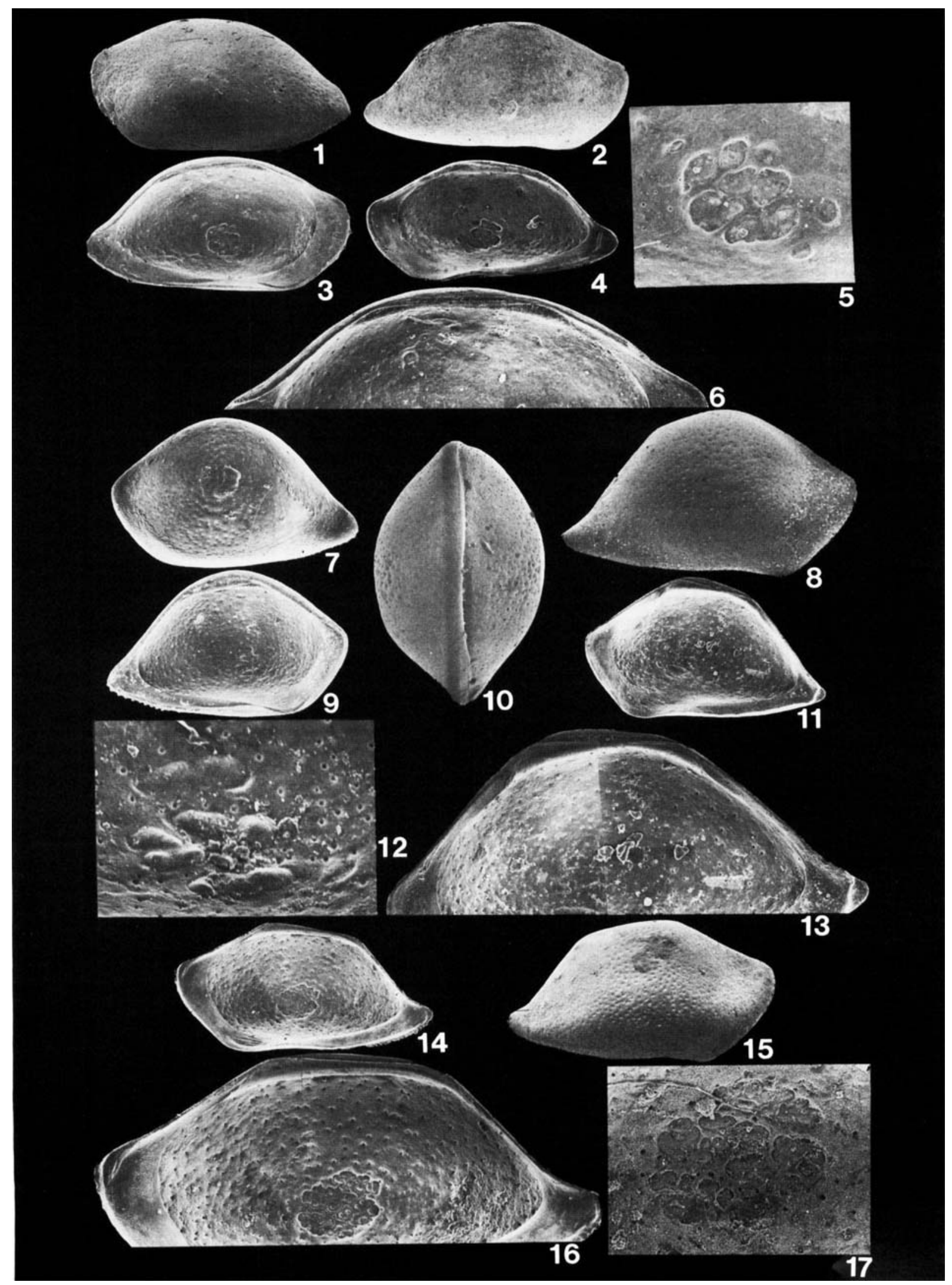


slope absent; posterodorsal slope almost straight, obliquely sloping. Dorsal margin gently convex in LV; short, straight in RV; cardinal angles rounded. Ventral margin almost straight. Maximum length subventral; maximum height at anterior $1 / 3$ of length; maximum width median. Valve surface smooth. Internal features typical of Neonesidea except unusual muscle scar pattern of 3 horizontal rows with 2 dorsal, 2 median and 1 ventral scar; scars appear to be fused.

Dimensions (mm)

$\begin{array}{llccc}\text { Holotype LV } & 1986.466 & 15 & 0.64 & 0.37 \\ \text { Paratype RV } & 1986.467 & 15 & 0.54 & 0.32 \\ \text { Paratype LV } & \text { RT/SIR/58 } & 33 & 0.59 & 0.33 \\ \text { Paratype RV } & 1986.468 & 55 & 0.62 & 0.34\end{array}$

Remarks. This species can only be tentatively placed in Neonesidea because of its unusual, subtrapezoidal shape and adductor muscle scar pattern. Neonesidea sp. 1 of Maddocks, 1969 recorded in Recent sediments from Nosy Bé, Madagascar, is of a similar shape but differs in muscle scar pattern and in possessing a caudal spine. Neonesidea dinochelata (Kornicker, 1961) from the Recent off Bimini, is also of a similar shape but is larger than the present species and the anteroventral slope is less broadly convex.

Distribution. Samples: 1, 14, 15, 32, 33, 54, 55, 56, 58, Guadalcanal.

\section{Neonesidea? sp. B}

(Fig. 6, No. 11; Pl. 44, Figs. 14-17)

Material. 5 specimens.

Dimensions $(\mathrm{mm})$

$\begin{array}{lccc} & \text { sample } & \text { length } & \text { height } \\ \text { RV RT/SIR/38 } & 17 & 0.79 & 0.39 \\ \text { RV RT/SIR/39 } & \text { OS6 } & 0.73 & 0.35 \\ \text { RV RT/SIR/40 } & \text { OS6 } & 0.77 & 0.38\end{array}$

Remarks. This species is most similar to $N$.? sp. aff. $N$. woodwardiana from the present material, and likewise has been tentatively placed in Neonesidea but the dorsal cardinal angles are more pronounced and the posterior extremity is more upswept. Further, this species is distinct as it possesses an unusual muscle-scar pattern as the scars have become highly sutured and marginally lobate, although the overall bairdioid pattern can still be recognised. A similar pattern occurs in Paranesidea petalona sp. nov., but this latter species has stronger ornament, is less acuminate posteriorly and more inflated ventrolaterally.

Distribution. Samples: 1, 17, OS6, Guadalcanal and Shortland Islands.

Genus Paranesidea Maddocks, 1969

Paranesidea algicola Maddocks, 1969

(Fig. 7, Nos. 1-2; Pl. 6, Figs. 1-9)

1969 Paranesidea algicola sp. nov. Maddocks: 46, figs. $22-24$; pl. 1 , figs. $7-8$.

Material. 200 specimens, adults and juveniles to A-3. Mean and range of dimensions $(\mathrm{mm})$

$\begin{array}{llcc} & \text { length } & \text { height } \\ 16 \mathrm{LV} & 0.71(0.67-0.77) & 0.44(0.39-0.48) \\ 29 \mathrm{RV} & 0.74(0.65-0.82) & 0.40(0.33-0.43) \\ 10 \mathrm{LV} \mathrm{A}-1 & 0.65(0.60-0.67) & 0.38(0.35-0.39) \\ 10 \mathrm{RV} \mathrm{A}-1 & 0.64(0.62-0.66) & 0.34(0.32-0.39) \\ 10 \mathrm{~A}-2 & 0.52(0.50-0.54) & 0.30(0.29-0.31) \\ 3 \mathrm{~A}-3 & 0.41(0.40-0.42) & 0.25(0.24-0.25)\end{array}$

Remarks. This species is characteristic of the genus and as such is difficult to distinguish from other species except by careful examination of the outline of both valves. Paranesidea parva Hartmann, 1978, from the Recent of Western Australia, is closest, but is less convex dorsally. Adult size measurements cluster into 2 groups, this is believed to reflect sexual dimorphism; the larger group represents the females. As soft parts are not preserved this cannot be proven, however, Maddocks (1969) gave size measurements for both sexes in which the females tended to be the larger. Precocious sexual dimorphism is not apparent.

\section{Explanation of Plate 5}

Figs. 1-9. Paranesidea? confusa sp. nov. : fig. 1, Paratype 1986.498 LV, ext. lat ( $\times$ 40); fig. 2, Paratype 1986.497 RV, ext. lat. $(\times 40)$; fig. 3 , Holotype $1986.496 \mathrm{LV}$, int. lat. $(\times 42)$; fig. 4, Paratype RT/SIR/47 Car, ext. dorsal $(\times 41)$; fig. 5, Paratype $1986.500 \mathrm{RV}$, int. lat. $(\times 45)$; fig. 6, Holotype $1986.496 \mathrm{LV}$, detail of hinge $(\times 106)$; fig. 7, Paratype RT/SIR/47 Car, detail of normal pore $(\times 2045)$; fig. 8, Holotype $1986.496 \mathrm{LV}$, detail of central muscle scars $(\times 197)$; fig. 9, Paratype $1986.500 \mathrm{RV}$, detail of hinge $(\times 81)$.

Figs. 10-14. Neonesidea? rara sp. nov.: fig. 10, Holotype 1986.466 LV, ext. lat. ( $\times 63)$; fig. 11, Paratype 1986.467 RV, ext. lat. $(\times 78)$; fig. 12, Holotype $1986.466 \mathrm{LV}$, int. lat. $(\times 68)$; fig. 13, Holotype $1986.466 \mathrm{LV}$, detail of central muscle scars $(\times 270)$; fig. 14, Holotype 1986.466 LV, detail of hinge $(\times 119)$.

Figs. 15-21. Paranesidea petalona sp. nov.: fig. 15, Holotype 1986.483 LV, ext. lat. ( $\times 45)$; fig. 16, Paratype 1986.484 RV, ext. lat. ( $\times 45)$; fig. 17, Paratype $1986.485 \mathrm{LV}$, int. lat $(\times 42)$; fig. 18, Paratype 1986.486 RV, int. lat. $(\times 42)$; fig. 19, Paratype 1986.487 LV, detail of central muscle scars $(\times 213)$, fig. 20, Paratype 1986.486 RV, detail of hinge $(\times 80)$; fig. 21 , Paratype 1986. $485 \mathrm{LV}$, detail of hinge $(\times 92)$. 

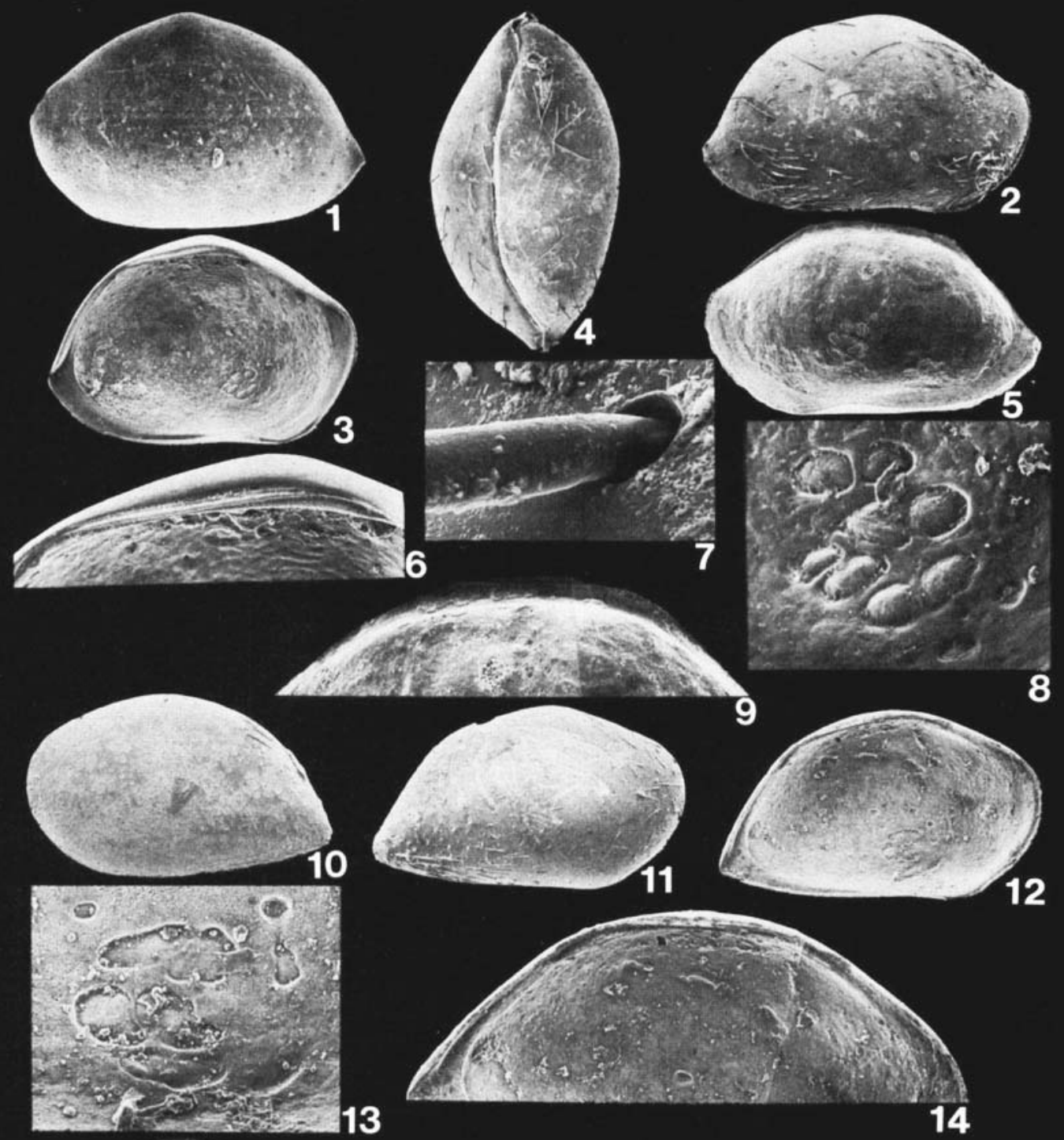

costonit?
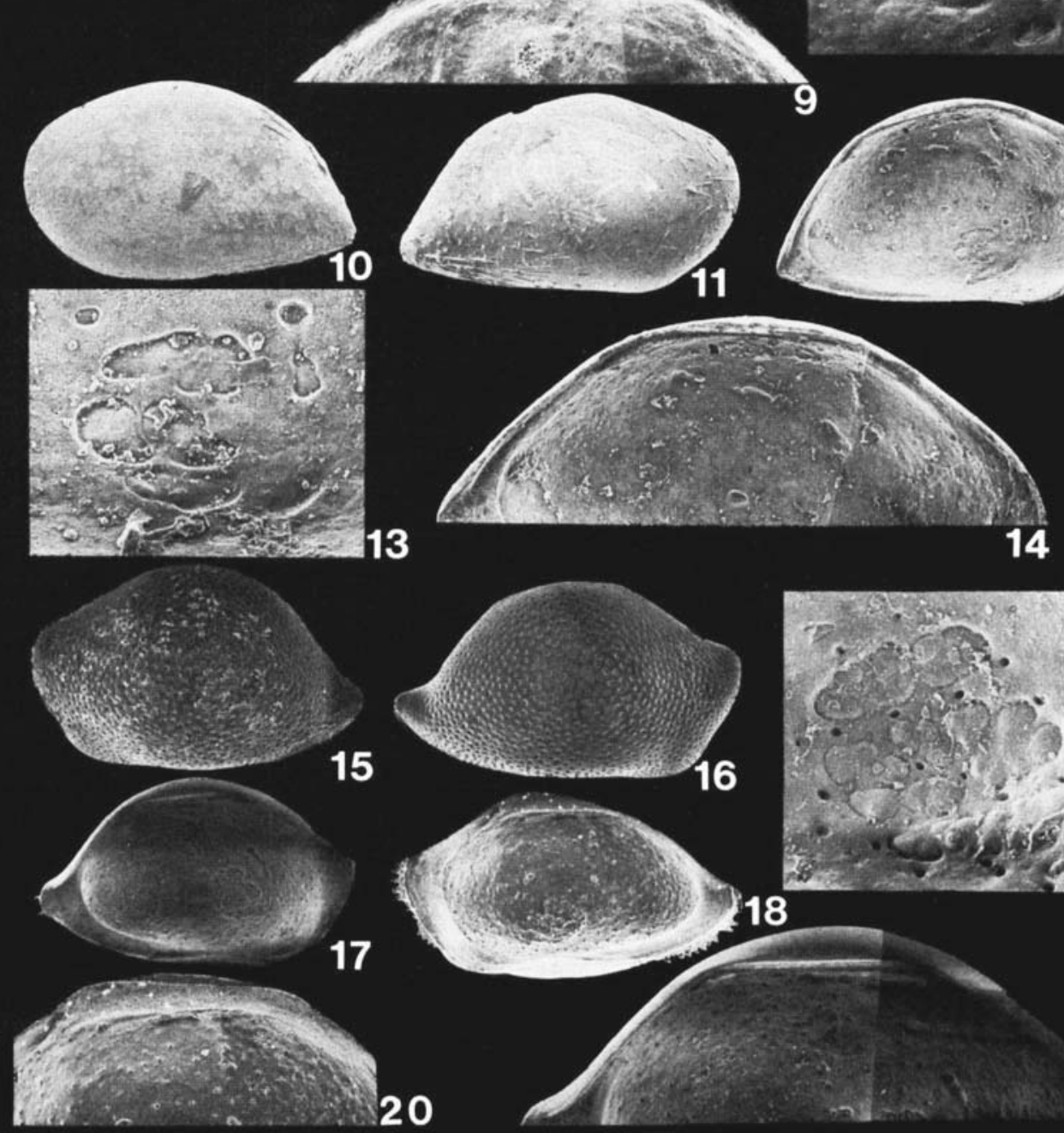

16

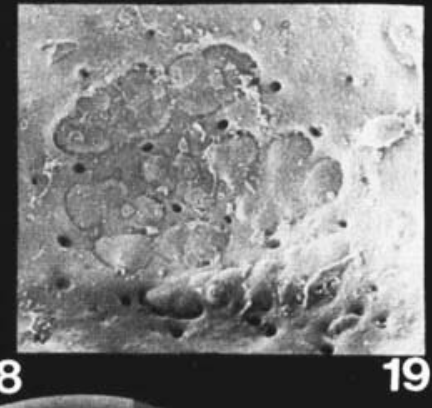

19 
Distribution. Recent. Shallow water, Nosy Bé, Madagascar (Maddocks, 1969). Samples: OS5, OS6, Shortland Island.

Paranesidea bipustulosa sp. nov.

(Fig. 7, Nos. 3-4; Pl. 6, Figs. 10-17)

Derivation of name. L. With reference to the pustules developed on the anterior and posterior lateral surfaces.

Diagnosis. Dorsal margin strongly convex in LV; posterior cavolate, slightly upturned; posterodorsal slope concave near extremity. 10-12 marginal denticles antero- and posteroventrally in LV; well developed marginal frill in RV. Valve surface with dense punctae; pustulose tubercles, variable in number, on anterior and posterior lateral surfaces, each beaing a large, simple pore. Internally, posterior margin truncate in $R V$, outlined by the sub-vertical selvage which is overreached by an extended flange.

Holotype. LV 1986.469.

Material. 169 specimens: 29 adults, 140 juveniles to A-3.

Type locality and horizon. Sample 14, 1,400 feet offshore west of Point Cruz, Honiara Bay, Guadalcanal, Solomon Islands. 10 fathoms. Medium coral sand. Recent.

Description. Large. Thick-shelled. Translucent with complex opaque patches: subcentral patch shaped like an amphora without handles, anteriorly and posteriorly large, irregular, trifurcating patches. Shape bairdioid in lateral view; subelliptical in dorsal. Anterior asymmetrically rounded; anterodorsal slope straight; anteroventral slope broadly convex with 12 marginal denticles in LV; strong, radially striate frill in RV. Posterior cavolate, slightly upturned, more so in RV; extremity just below mid-height. Posterodorsal slope gently convex to strongly concave near extremity; posteroventral slope convex with 10 digitate marginal denticles in LV and strong, radially striate frill in RV. Dorsal margin strongly convex in LV, straight in RV; cardinal angles rounded in $\mathrm{LV}$, pronounced in RV. Ventral margin gently convex in LV; biconvex in RV. Maximum length just below mid-height; maximum height median in LV, anterior to mid-length in RV; maximum width median. Lateral surface covered with dense circular punctae which decrease in size peripherally, absent around margins. Pustules variably developed on anterior and posterior lateral surfaces, each with large, simple pore. Normal pore canals large, simple, not within punctae. Internal features characteristic of genus.

Dimensions $(\mathrm{mm})$

$\begin{array}{lrrrr}\text { Holotype LV } & 1986.469 & 14 & 0.87 & 0.57 \\ \text { Paratype RV } & 1986.470 & 1 & 0.89 & 0.46\end{array}$

\begin{tabular}{|c|c|c|c|c|}
\hline Paratype RV & 1986.471 & 15 & 0.94 & 0.54 \\
\hline Paratype LV & 1986.472 & 2 & 0.86 & 0.57 \\
\hline Paratype RV & 1986.473 & 1 & 0.90 & 0.51 \\
\hline Paratype LV & $\mathrm{RT} / \mathrm{SIR} / 79$ & 62 & 0.88 & 0.58 \\
\hline Paratype Car. & RT/SIR/80 & 2 & 0.90 & $\begin{array}{ll}0.60 & 0.48\end{array}$ \\
\hline \multicolumn{5}{|c|}{$\begin{array}{c}\text { Mean and range of dimensions } \\
\text { length }\end{array}$} \\
\hline 2 Car. & $0.89,0.92$ & & $0.57,0.6$ & $10.46,0.49$ \\
\hline $5 \mathrm{~L}$ & $87(0.85-0.91)$ & & 8 & $.61)$ \\
\hline $18 \mathrm{RV}$ & $87(0.81-0.97)$ & & 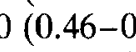 & $.55)$ \\
\hline $20 \mathrm{LV}$ A-1 0 & $71(0.68-0.74)$ & & $6(0.44-$ & $0.49)$ \\
\hline $17 \mathrm{RV} \mathrm{A}-10$. & $70(0.69-0.73)$ & & $\left(0^{\prime}\right.$ & $0.45)$ \\
\hline $17 \mathrm{~A}-2$ & $55(0.49-0.57)$ & & & 36) \\
\hline $7 \mathrm{~A}-3$ & $41(0.38-0.42)$ & & (ก) & 27) \\
\hline
\end{tabular}

Remarks. This species is similar to both $P$. spongicola and $P$. fracticorallicola Maddocks, 1969, from Madagascar. The posterior extremity in $P$. spongicola, however, is less upturned and the pattern of the opaque patches differs in that they are all joined. The most conspicuous difference between this species and $P$. fracticorallicola is that the maximum width of the carapace is median, and not ventral, it is also relatively higher.

Distribution. Quaternary, Guadalcanal and Shortland Islands (Williams, 1980, MS). Samples: 1, 2, 14, 15, 16, $17,19,20,30,32,33,53,55,56,57,58,60,62$, OS5, OS6, Guadalcanal and Shortland Islands.

\section{Paranesidea corbita sp. nov.}

(Pl. 7, Figs. 1-6)

Derivation of name. $\mathrm{L}$. With reference to the shape of this species which resembles a cumbersome boat.

Diagnosis. Shape of LV suboval in lateral view; RV typically bairdioid; posterior cavolate, upswept in both valves, extremity about mid-height. Strong, spinose marginal denticles antero- and posteroventrally in LV, strong marginal frill in RV. Valve surface with deep and dense punctae. Feebly translucent without opaque patches.

Holotype. LV 1986.474.

Material. 53 valves: 16 adults, 37 juveniles to $\mathrm{A}-4$. Type locality and horizon. Sample 2, 500 feet offshore west of Point Cruz, Honiara Bay, Guadalcanal, Solomon Islands, 1.5 fathoms. Medium coral sand. Recent. Description. Large. Thick-shelled. Feebly translucent without opaque patches. Shape of LV suboval in lateral view; RV typically biardioid; elliptical in dorsal view. Anterior asymmetrically rounded; anterodorsal slope gently concave, anteroventral slope broady convex with 10 robust, spinose marginal denticles in $\mathrm{LV}$, strong marginal frill in RV; apex an obtuse angle above mid-height. Posterior cavolate, upswept in both valves; posterodorsal slope straight becoming strongly concave near extremity; posteroventral slope convex with 14 , strong, spinose marginal denticles in LV, strong mar- 


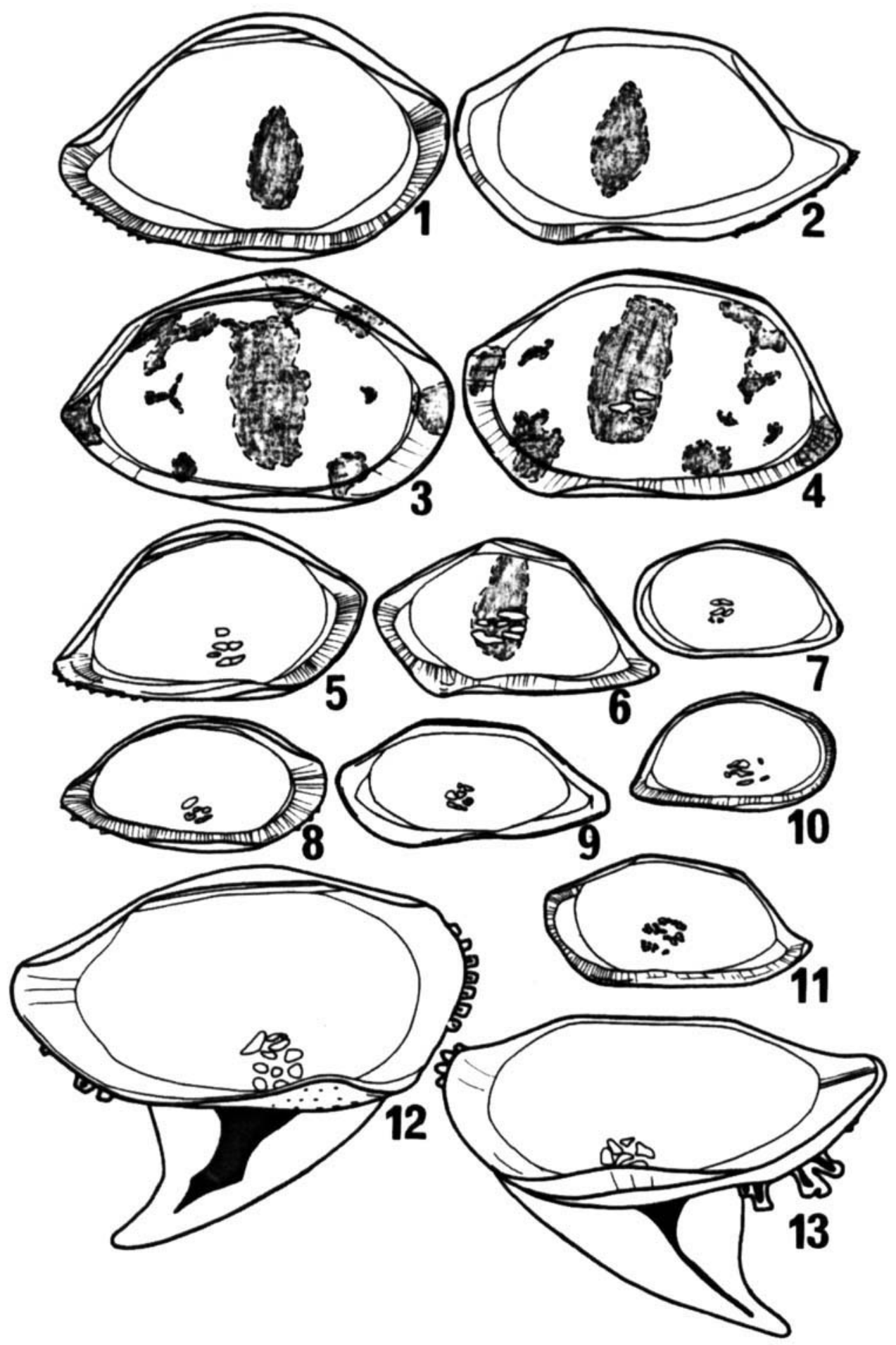

Fig. 6. Neonesidea sp. A. 1, RT/SIR/32 LV, int. lat $(\times 50) ; 2, \mathrm{RT} / \mathrm{SIR} / 31 \mathrm{RV}$, int. lat. $(\times 52)$. Paranesidea? confusa sp. nov. 3, Paratype RT/SIR/54 LV, int. lat. $(\times 52)$; 4, Paratype RT/SIR/53 RV, int. lat. $(\times 50)$. Neonesidea? crepidula sp. nov. 5, Holotype $1986.460 \mathrm{LV}$, int. lat. $(\times 53) ; 6$, Paratype $1986.462 \mathrm{RV}$, int. lat. $(\times 50)$. Neonesidea? rara sp. nov. 7, Paratype $1986.468 \mathrm{RV}$, int. lat. $(\times 49) ; 10$, Paratype RT/SIR/58 LV, int. lat. $(\times 50)$. Neonesidea? sp. aff. N. woodwardiana (Brady, 1880). 8, RT/SIR/36 IV, int. lat. (×52); 9, RT/SIR/34 RV, int. lat. $(\times 51)$. Neonesidea? sp. B. 11, RT/SIR/39 RV, int. lat. $(\times 53)$. Pterobairdia briggsae McKenzie, 1986.12 , $\mathrm{RT} / \mathrm{SIR} / 135 \mathrm{LV}$, int. lat. $(\times 87) ; 13, \mathrm{RT} / \mathrm{SIR} / 136 \mathrm{RV}$, int. lat. $(\times 88)$. 
ginal frill in RV; posterior extremity at mid-height in $\mathrm{LV}$, just below mid-height in RV. Dorsal margin strongly convex in LV; straight in RV; cardinal angles pronounced in RV only. Ventral margin gently biconvex; oral concavity shallow. Maximum length just below mid-height; maximum height median in $\mathrm{LV}$, at anterior $1 / 3$ of length in RV; maximum width median. Valve surface with deep and dense, circular punctae, which are concentric about mid-point. Internal features characteristic of genus.

Dimensions (mm)

\begin{tabular}{llllll}
\multicolumn{5}{c}{ sample length height } & width \\
Holotype LV & 1986.474 & 2 & 0.82 & 0.58 & \\
Paratype Car. RT/SIR/85 & 19 & 0.77 & 0.51 & 0.39 \\
Paratype RV & 1986.475 & 2 & 0.85 & 0.45 & \\
Paratype LV & 1986.476 & 2 & 0.83 & 0.55 & \\
Paratype RV & 1986.477 & 2 & 0.83 & 0.40 & \\
Paratype LV RT/SIR/90 20 & 0.85 & 0.57 \\
Mean and range of dimensions & $(\mathrm{mm})$ \\
\multicolumn{5}{c}{ length } \\
7 LV & $0.81(0.78-0.85)$ & $0.53(0.49-0.58)$ \\
3 RV & $0.83(0.81-0.85)$ & $0.43(0.42-0.46)$ \\
10 LV A-1 & $0.69(0.67-0.71)$ & $0.42(0.40-0.45)$ \\
6 RV A-1 & $0.71(0.70-0.71)$ & $0.39(0.38-0.41)$ \\
9 A-2 & $0.54(0.50-0.58)$ & $0.31(0.30-0.33)$ \\
7 A-3 & $0.44(0.41-0.46)$ & $0.26(0.25-0.27)$ \\
1 A-4 & 0.34 & 0.20
\end{tabular}

Remarks. This species is closest to $P$. stricta sp. nov. but the posterior is more upswept, the punctae are less deeply incised subcentrally, the marginal denticulation is stronger and the valves are less inflated. The upswept cavolate posterior distinguishes it from those species of the genus described by Maddocks (1969) from the Recent of Nosy Bé, Madagascar except Paranesidea sp. 4. The present species differs in that the anterior and posterior extremities are slightly lower. The posterior extremity of $P$. onslowensis Hartmann, 1978, described from the western coast of Australia, is less extended and the surface ornament is finer.

Like $P$. algicola in the present material, the range in size observed, particularly of the adult left valves, may reflect sexual dimorphism.

Distribution. Samples: 1, 2, 13, 14, 15, 17, 19, 20, 29 , $32,54,57,58,60$, Guadalcanal.

Paranesidea equipunctata sp. nov.

(Fig. 7, Nos. 5-6; Pl. 7, Figs. 7-13)

Derivation of name. L. With reference to the regular nature of the punctae which comprise the ornament of this species.

Diagnosis. Shape of LV elongate, suboval in lateral view; RV typically bairdioid. Dorsal margin broadly convex in $\mathrm{LV}$; posterior bluntly caudate in $\mathrm{LV}$; cavolate and gently upturned in RV. Posterodorsal slope more strongly concave near posterior extremity in
RV than in LV. Valve surface with deep, dense punctae, of equal size. Narrow marginal frill on anteroand posteroventral margins, opaque patches absent.

Holotype. LV 1986.478.

Material. 16 specimens: all adults.

Type locality and horizon. Sample OS6. Exact location unknown but thought to be from the intertidal zone, near a coral reef, off the north-east coast of Shortland Island, Solomon Islands, in the vicinity of Rokuai Island. Coarse coral sand. Recent.

Description. Large. Very thick-shelled. Feebly translucent without opaque patches. Shape of LV elongate, suboval in lateral view; RV typically bairdioid; elliptical in dorsal view. Anterior asymmetrically rounded; anterodorsal slope almost straight to gently concave near extremity; anteroventral slope broadly convex with narrow, strong marginal frill in both valves; apex an obtuse angle well above mid-height. Posterior bluntly caudate in LV; cavolate, slightly upturned in RV; extremity just below mid-height. Posterodorsal slope convex becoming concave near extremity in LV, straight to becoming concave near extremity in RV. Posteroventral slope concave with narrow marginal frill in RV. Dorsal margin broadly convex in LV; straight in $\mathrm{RV}$; cardinal angles more pronounced in RV. Ventral margin almost straight in LV; biconvex in RV. Maximum length at about mid-height; maximum height median in LV, at anterior $1 / 3$ of length in RV. Valve surface covered with deep, dense, circular punctae of equal size, concentric about mid-point. Internal features typical of genus.

Dimensions (mm)

$\begin{array}{lcccc} & & \text { sample } & \text { length } & \text { height } \\ \text { Holotype LV } & 1986.478 & \text { OS6 } & 0.90 & 0.56 \\ \text { Paratype RV } & 1986.479 & \text { OS6 } & 0.91 & 0.47 \\ \text { Paratype RV } & 1986.480 & \text { OS6 } & 0.92 & 0.47 \\ \text { Paratype LV } & 1986.481 & \text { OS6 } & 0.87 & 0.53 \\ \text { Paratype RV } & 1986.482 & \text { OS6 } & 0.89 & 0.48\end{array}$
Mean and range of dimensions $(\mathrm{mm})$

$\begin{array}{lcc} & \text { length } & \text { height } \\ 6 \mathrm{RV} & 0.90(0.85-0.94) & 0.46(0.43-0.51)\end{array}$

Remarks. This species most closely resembles $P$. spongicola in the present material, but the posterior extremity is more dorsal, the dorsal margin is longer and the anterodorsal slope correspondingly shorter. The marginal frill in the RV is less well developed and the present species is approximately $0.15 \mathrm{~mm}$ longer. In addition, $P$. spongicola differs in that the valves are thickened around the anterior and posterior margins. Distribution. Sample: OS6, Shortland Island.

Paranesidea petalona sp. nov.

(Fig. 7, Nos. 7-8; Pl. 5, Figs. 15-21)

Derivation of name. Gr. With reference to the petallike shape of the central muscle scars. 


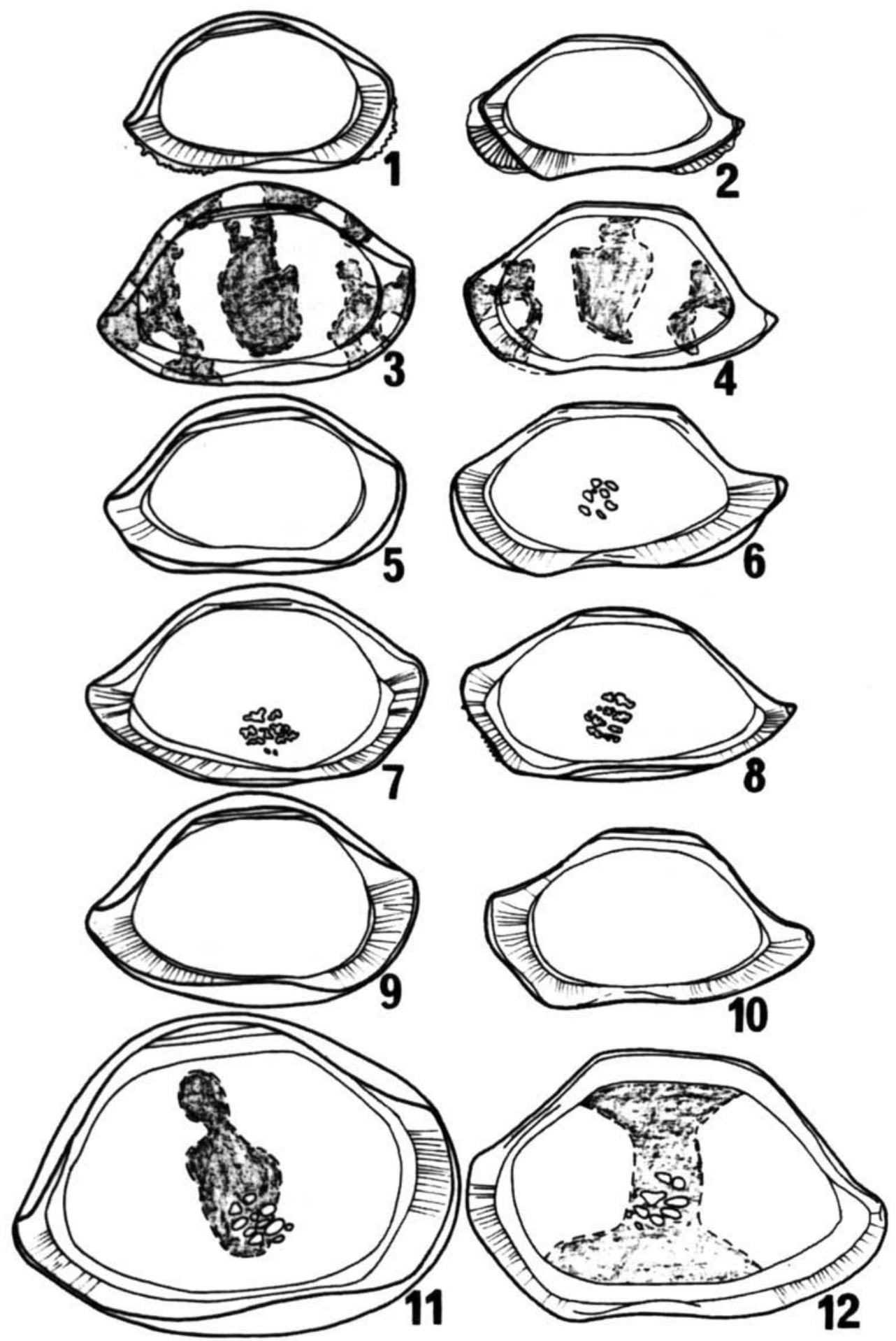

Fig. 7. Paranesidea algicola Maddocks, 1969. 1, RT/SIR/67 LV, int. lat. $(\times 52) ; 2$, RT/SIR/66 RV, int. lat. $(\times 57)$. Paranesidea bipustulosa sp. nov. 3, Paratype RT/SIR/79 LV, int. lat. $(\times 52)$; 4, Paratype 1986.473 RV, int. lat. ( $\times 51$ ). Paranesidea equipunctata sp. nov. 5, Paratype 1986.481 LV, int. lat. ( $\times 51)$; 6, Paratype 1986.482 RV, int. lat. $(\times 55)$. Paranesidea petalona sp. nov. 7, Paratype RT/SIR/96 LV, int. lat $(\times 52)$; Paratype RT/SIR/97 RV, int. lat. $(\times 52)$. Paranesidea stricta sp. nov. 9, Holotype $1986.488 \mathrm{LV}$, int. lat. $(\times 53) ; 10$, Paratype RT/SIR/84 RV, int. lat. (×52). Paranesidea? sp. cf. P. globulus (Brady, 1880); 11, RT/SIR/105 LV, int. lat. $(\times 71) ; 12, \mathrm{RT} / \mathrm{SIR} / 106 \mathrm{RV}$, int. lat. $(\times 79)$. 
Diagnosis. Typically bairdioid in shape. Valve surface densely punctate, punctae becoming smaller peripherally but denser. 8-10 strong marginal spines anteroand posteroventrally in LV; marginal frill with denticles antero- and posteroventrally in RV. CMS pattern an ovate patch of highly sutured and marginally lobate scars, the bairdioid pattern recognisable.

Holotype. LV 1986.483.

Material. 49 specimens: 11 adults, 38 juveniles to A-3. Type locality and horizon. Sample 13, 1,800 feet offshore west of Point Cruz, Honiara Bay, Guadalcanal. 11 fathoms. Medium coral sand. Recent.

Description. Large. Thick-shelled. Translucent. Typically bairdioid in shape in lateral view; subelliptical in dorsal view. Anterior asymmetrically rounded; anterodorsal slope gently concave, anteroventral slope gently convex becoming concave ventrally with 8 strong spinose denticles in LV; 12 smaller denticles extending from marginal frill in RV; apex a rounded right angle well above mid-height. Posterior acuminate; extremity just below mid-height, more sharply rounded in RV. Posterodorsal slope straight to concave near extremity; posteroventral slope gently convex with 7 spinose denticles in LV and marginal frill with ragged denticles in RV. Dorsal margin convex in $\mathrm{LV}$, straight in RV; cardinal angles rounded in $L V$, pronounced in $R V$. Ventral margin gently biconvex. Maximum length just below mid-height; maximum height median in LV, at anterior $1 / 3$ of length in $\mathrm{RV}$; maximum width median. Valve surface densely punctate; punctae decrease in size peripherally but are denser. Internal features characteristic of genus, except for central muscle scar pattern which comprises a large oval patch of highly sutured and marginally lobate scars.

Dimensions ( $\mathrm{mm}$ )

$\begin{array}{llrrr}\text { Holotype LV } & 1986.483 & 13 & 0.90 & 0.55 \\ \text { Paratype RV } & 1986.484 & 15 & 0.91 & 0.49 \\ \text { Paratype LV } & 1986.485 & 30 & 0.92 & 0.57 \\ \text { Paratype RV } & 1986.486 & 57 & 0.92 & 0.50 \\ \text { Paratype LV } & 1986.487 & 14 & 0.90 & 0.54 \\ \text { Paratype LV } & \text { RT/SIR/96 } & 2 & 0.94 & 0.56 \\ \text { Paratype RV } & \text { RT/SIR/97 } & 2 & 0.93 & 0.49\end{array}$

$\begin{array}{rlcc}\text { Mean and range of dimensions }(\mathrm{mm}) & \text { height } \\ & \text { length } & \text { height } \\ 6 \mathrm{LV} & 0.92(0.89-0.96) & 0.57(0.54-0.58) \\ 4 \mathrm{RV} & 0.92(0.89-0.93) & 0.50(0.49-0.50) \\ 4 \mathrm{LV} \mathrm{A}-1 & 0.75(0.74-0.76) & 0.45(0.45-0.46) \\ 5 & \mathrm{RV} \mathrm{A}-1 & 0.74(0.73-0.74) & 0.42(0.40-0.43) \\ 12 \mathrm{~A}-2 & 0.56(0.54-0.58) & 0.33(0.31-0.35) \\ 4 \mathrm{~A}-3 & 0.42(0.40-0.43) & 0.25(0.25-0.26)\end{array}$

Remarks. The unusual, complex central muscle scar pattern of highly sutured scars is very distinctive. A similar pattern was observed in Neonesidea. sp. B in the present material but the present species differs in being more strongly ornamented, less acuminate posteriorly and more inflated ventrolaterally. Nesidea mulleri Fyan, 1916 from the Timor Pliocene, is about $0.5 \mathrm{~mm}$ longer and the LV is less high than the present species.

The adult valves of this species are all of similar size. Distribution. Samples: 1, 2, 13, 14, 15, 16, 17, 30, 41, $54,57,58$, Guadalcanal.

Paranesidea stricta sp. nov.

(Fig. 7, Nos. 9-10; Pl. 7, Figs. 14-17)

Derivation of name. Gr. With reference to the surface ornament, which appears to be punctured all over. Diagnosis. Typically bairdioid in shape; valves strongly inflated ventrolaterally, robust. Posterior excavated, extremity well below mid-height; anterodorsal slope gently concave. Valve surface with deep, dense punctae. Opaque. Marginal denticulation weakly developed. Selvage peripheral, forms small "notch" at posterior extremity in RV.

Holotype. LV 1986.488.

Material. 22 specimens: 12 adults, 10 juveniles to $\mathrm{A}-2$. Type locality and horizon. Sample OS6. Exact location unknown but thought to be from the intertidal zone, near a coral reef, off the north-east coast of Shortland Island, Solomon Islands, in the vicinity of Rokuai Island. Coarse coral sand. Recent.

Description. Large. Very thick-shelled. Opaque. Shape typically bairdioid in lateral view; subelliptical in dorsal view, strongly inflated ventrolaterally. Anterior asymmetrically rounded; anterodorsal slope gently concave;

\section{Explanation of Plate 6}

Figs. 1-9. Paranesidea algicola Maddocks: fig. 1, RT/SIR/61 LV (large), ext. lat. $(\times 60)$; fig. 2, RT/SIR/62 RV (large), ext. lat. $(\times 60)$; fig. 3, RT/SIR/64 LV (small), ext. lat. $(\times 60)$; fig. 4, RT/SIR/60 Car (large), ext. dorsal ( $\times 62)$; fig. RT/SIR/63 Car (small), ext. dorsal ( $\times 63$ ); fig. 6, RT/SIR/65 RV (small), ext. lat. $(\times 60)$; fig. 7 , RT/SIR/67 LV, int. lat. ( $\times 64)$; fig. $8, \mathrm{RT} / \mathrm{SIR} / 66 \mathrm{RV}$, detail of central muscle scars $(\times 220)$; fig. $9, \mathrm{RT} / \mathrm{SIR} / 66$ RV, int. lat. $(\times 62)$.

Figs. 10-17. Paranesidea bipustulosa sp. nov.: fig. 10, Holotype 1986.469 LV, ext. lat. ( $\times 48)$; fig. 11, Paratype 1986.470 RV, ext. lat. ( $\times 49)$; fig. 12, Paratype 1986.472 LV, int. lat. $(\times 49)$; fig. 13, Paratype RT/SIR/73 Car, ext. dorsal ( $\times 45)$; fig. 14, Paratype 1986.471 RV, int. lat. (×48); fig. 15, Paratype 1986.472 LV, detail of hinge ( $\times 85)$; fig. 16, Paratype $1986.473 \mathrm{RV}$, detail of central muscle scars $(\times 242)$; fig. 17, Paratype 1986.471 RV, detail of hinge $(\times 99)$. 


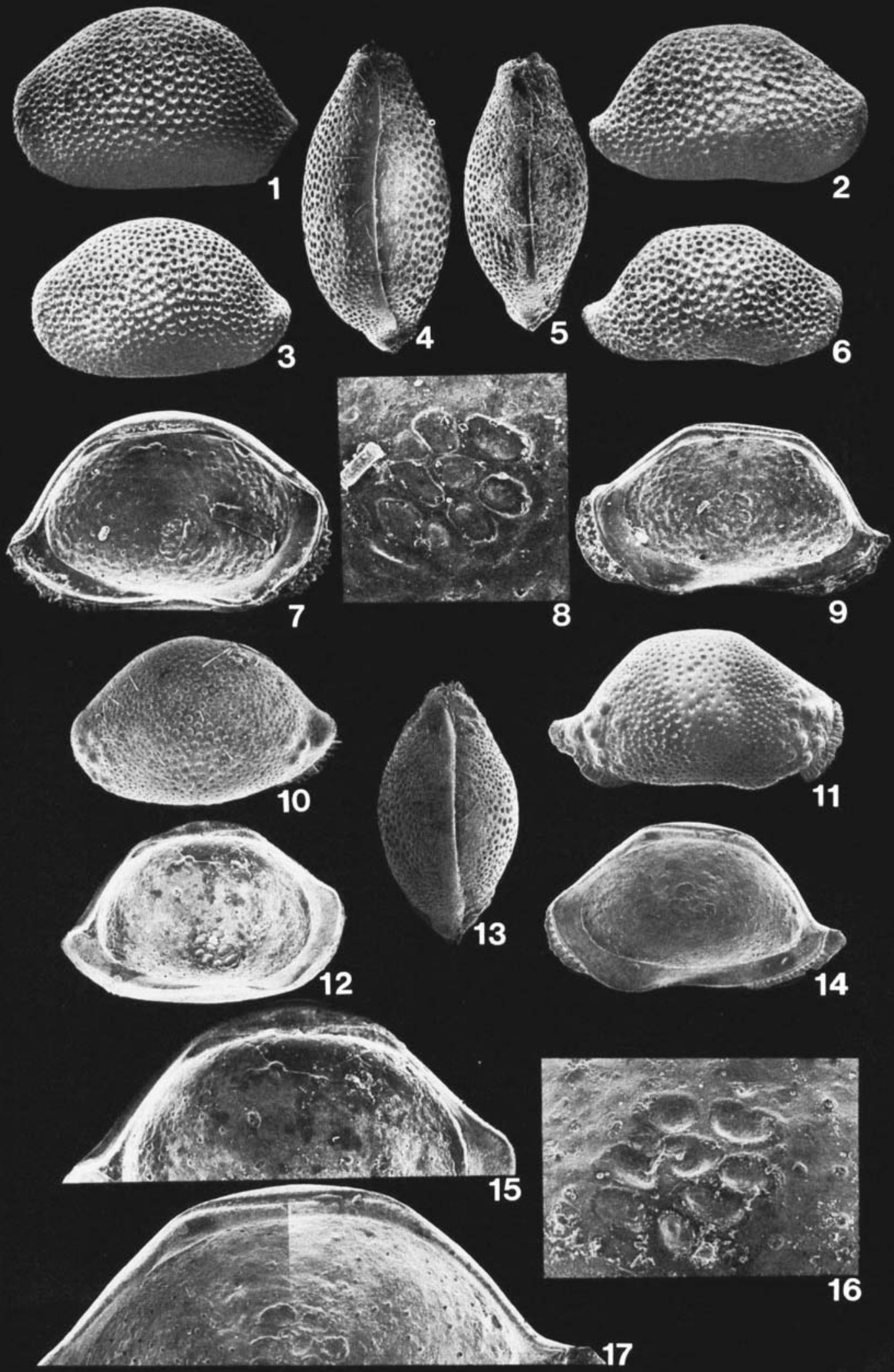


anteroventral slope broadly convex with weak marginal denticles; apex a rounded right angle well above mid-height. Posterior cavolate, extremity well below mid-height; posterodorsal slope straight becoming concave near extremity, concavity more pronounced in RV; posteroventral slope convex with narrow, delicate marginal frill near extremity in RV only. Dorsal margin convex in LV; straight in RV; cardinal angles rounded in $\mathrm{LV}$; pronounced in RV. Ventral margin biconvex; obscured by lateral inflation in LV. Maximum length at mid-height; maximum height median in $\mathrm{LV}$, at anterior $1 / 3$ of length in RV; maximum width median. Lateral surface covered by very deep, dense punctae which are slightly larger and less densely distributed subcentrally; concentrically arranged around mid-point. Internal features typical of genus.

Dimensions $(\mathrm{mm})$

$\begin{array}{lllll}\text { Holotype LV } & 1986.488 & \text { OS6 } & 0.89 & 0.55 \\ \text { Paratype RV } & 1986.489 & \text { OS6 } & 0.94 & 0.52 \\ \text { Paratype RV } & 1986.490 & \text { OS6 } & 0.90 & 0.51 \\ \text { Paratype RV } & \text { RT/SIR/84 } & \text { OS6 } & 0.92 & 0.52\end{array}$

Remarks. This species most closely resembles $P$. petalona sp. nov. but is more deeply punctate, less caudate posteriorly, the dorsal margin is less broad and the muscle scars are not sutured.

Distribution. Sample OS6, Shortland Island.

Paranesidea? confusa sp. nov.

(Fig. 6, Nos. 3-4; Pl. 5, Figs. 1-9)

Derivation of name. $L$. With reference to the uncertain taxonomic status of this species.

Diagnosis. Shape of LV subtriangular in lateral view; RV subquadrate: subelliptical in dorsal view. LV dorsal margin angularly convex. Posterior bluntly caudate; extremity acutely rounded in LV. Complex pattern of opaque patches with large, suboval central patch and surrounded by smaller variable, irregular patches. Narrow, delicate marginal frill antero- and posteroventrally in RV. Valve surface with dense, minute punctae. Selvage peripheral, forming a small "notch" at posterior extremity in RV.

Holotype. LV 1986.496.

Material. 81 specimens: 20 adults, 41 juveniles to A-3. Type locality and horizon. Sample OS3, Katufe Island, off the north-east coast of Shortland Island. Medium coral sand from coral reef. Recent.

Description. Large to very large. Moderately thickshelled. Translucent with a complex pattern of opque patches: large central patch irregular, suboval surrounded by many variable, irregular patches. Shape of LV subtriangular in lateral view; RV subquadrate: subelliptical in dorsal view. Anterior asymmetrically rounded: anterodorsal slope slightly convex in LV, almost straight in RV; anteroventral slope convex; apex rounded; obtuse, just above mid-height: RV with narrow, delicate marginal frill anteroventrally. Posterior bluntly caudate, extremity well below mid-height, more acutely rounded in LV. Posterodorsal slope convex to gently concave towards extremity; posteroventral slope convex. LV with 10-12 small, triangular marginal denticles, RV with narrow, delicate marginal frill posteroventrally. Dorsal margin angularly convex in LV; straight, obliquely sloping to posterior in $\mathrm{RV}$; cardinal angles rounded. Ventral margin almost straight in LV; biconvex in RV. Maximum length well below mid-height; maximum height median in $\mathrm{LV}$, at anterior $1 / 3$ of length in RV; greatest width at anterior $1 / 3$ of length. Valve surface with dense, minute punctae. Internal features, in particular the central muscle scar pattern characteristic of Paranesidea.

Dimensions (mm)

\begin{tabular}{|c|c|c|c|c|}
\hline & sample & lengtł & height & wid \\
\hline Holotype LV 1986.496 & OS3 & 1.07 & 0.68 & \\
\hline Paratype LV 1986.498 & OS3 & 1.11 & 0.73 & \\
\hline Paratype RV 1986.497 & OS3 & 1.12 & 0.67 & \\
\hline Paratype RV 1986.500 & OS5 & 1.03 & 0.60 & \\
\hline Paratype LV RT/SIR/52 & OS4 & 1.10 & 0.71 & \\
\hline Paratype RV RT/SIR/53 & OS5 & 1.10 & 0.66 & \\
\hline Paratype LV RT/SIR/54 & OS5 & 1.09 & 0.67 & \\
\hline Paratype Car.1986.499 & OS5 & 1.08 & 0.71 & $\theta^{\prime}$ \\
\hline
\end{tabular}

Holotype LV 1986.496

Paratype LV 1986.498

Paratype RV 1986.497

1986.500

sample length height width OS3 $1.07 \quad 0.68$

OS3 $1.11-0.73$

0.67

Paratype LV RT/SIR/52 OS4 $1.10 \quad 0.71$

Paratype RV RT/SIR/53 OS5

Paratype Car. 1986.499 OS5 $1.08 \quad 0.71$

\section{Explanation of Plate 7}

Figs. 1-6. Paranesidea corbita sp. nov.: fig 1, Holotype 1986.474 LV, ext. lat. (× 44); fig. 2, Paratype 1986.475 RV, ext. lat. $(\times 45)$; fig. 3, Paratype RT/SIR/85 Car, ext . dorsal $(\times 49)$; fig. 4, Paratype $1986.476 \mathrm{LV}$, int. lat. $(\times 48)$; fig. 5, Paratype 1986.477 RV, int. lat. $(\times 49)$; fig. 6, Paratype $1986.477 \mathrm{RV}$, detail of central muscle scars $(\times 248)$.

Figs. 7-13. Paranesidea equipunctata sp. nov. fig. 7, Paratype 1986.479 RV, detail of lateral ornament $(\times 409)$; fig. 8 , Holotype 1986.478 LV, ext. lat. (× 49); fig. 9, Paratype 1986.479 RV, ext. lat. ( $\times 51)$; fig. 10, Holotype 1986.478 $\mathrm{LV}$, int. lat. ( $\times 48)$; fig. 11, Paratype $1986.480 \mathrm{RV}$, int. lat. ( $\times 49)$; fig. 12, Holotype $1986.478 \mathrm{LV}$, detail of central muscle scars $(\times 154)$; fig. 13, Holotype $1986.478 \mathrm{LV}$, detail of hinge $(\times 82)$.

Figs. 14-17. Paranesidea stricta sp. nov.: fig. 14, Holotype 1986.488 LV, ext. lat. (× 40); fig. 15, Paratype 1986.489 RV, ext. lat. $(\times 40)$; fig. 16, Paratype $1986.490 \mathrm{RV}$, int. lat. $(\times 44)$; fig. 17, Paratype $1986.490 \mathrm{RV}$, detail of central muscle scars $(\times 228)$. 
Recent Bairdiinae from the Solomon Islands

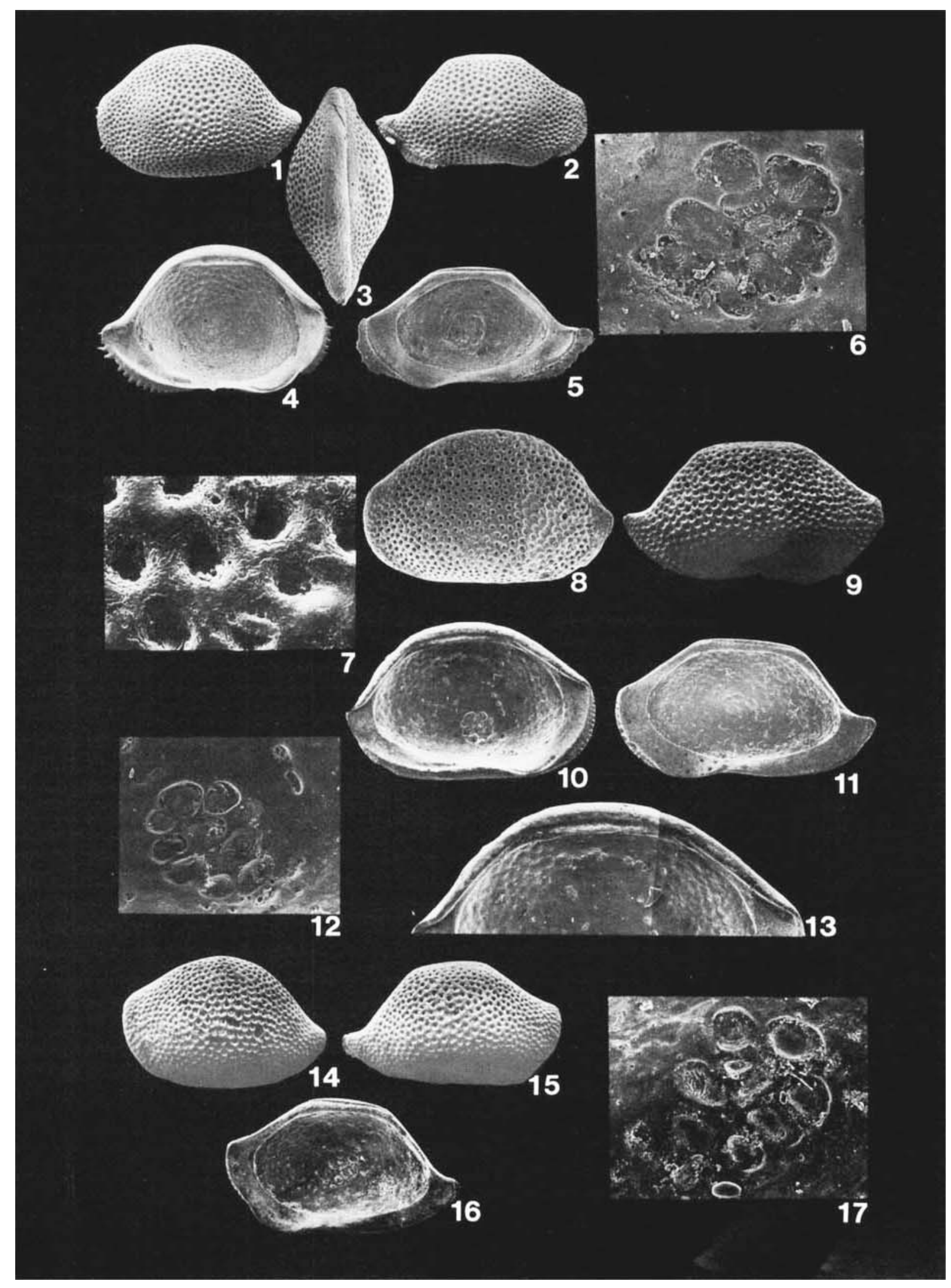




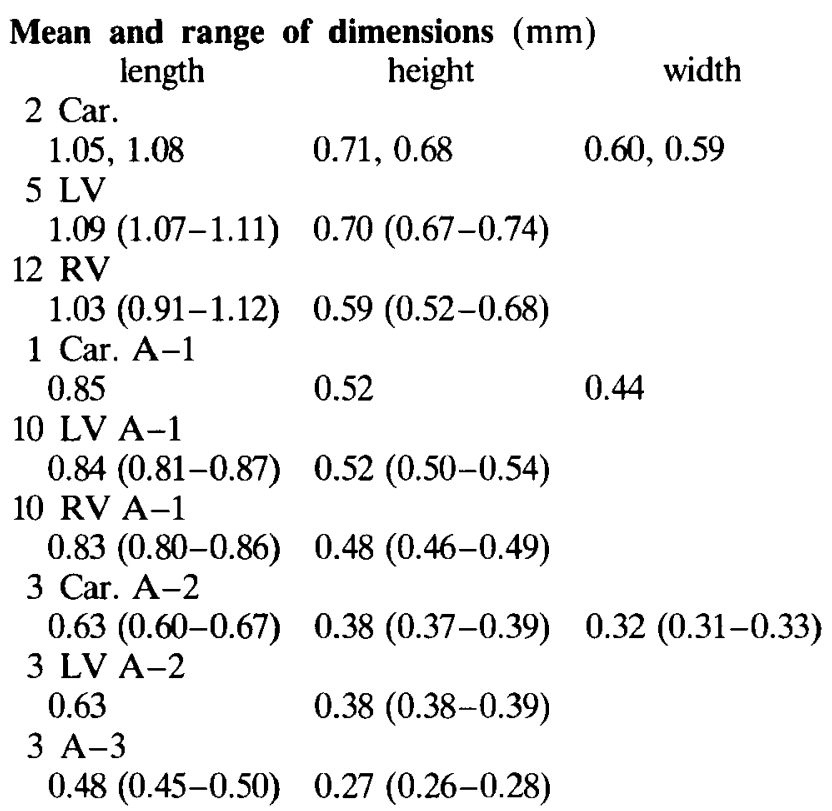

Remarks. The muscle scar pattern and marginal denticulation of this species is typical of Paranesidea but the surface ornament of very fine punctae and shape of the LV are more typical of Neonesidea. Neonesidea parilihamata Maddocks, 1969 recorded from Madagascar is similar in shape but the dorsal margin is less angularly convex and the muscle scar pattern differs.

The adults vary greatly in size, although the $\mathrm{A}-1$ instars are all of a similar size.

Distribution. Samples: 13, 15, 17, 30, 58, OS3, OS4, OS5, OS6, Guadalcanal and Shortland Islands.

Paranesidea? paucipunctata sp. nov.

(Fig. 7, Nos. 11-12; Pl. 8, Figs. 1-9)

Derivation of name. L. Referring to the sparsely punctate surface of the adult.

Diagnosis. LV suboval in lateral view, RV typically bairdoid; strongly inflated dorsally. Very robust. Translucent with large subcentral opaque patch; skittle-shaped in LV; larger, capstan-shaped in RV. Valve surface with fine, sparse punctae in adults and $\mathrm{A}-1$ juveniles; stronger punctae in younger juveniles. Caud- al spine and small marginal spine antero- and posteroventrally in LV.

Holotype. LV 1986.491.

Material. 133 valves: 29 adults, 104 juveniles to A-4. Type locality and horizon. Sample 17.

Description. Large to very large. Very thick-shelled. Translucent with large subcentral opaque patch, skittle shaped in LV, larger, capstan-shaped extending to dorsal and ventral margins in RV. LV suboval in shape in lateral view, RV typically bairdioid. Anterior asymmetrically rounded; anterodorsal slope almost straight, gently convex in $\mathrm{LV}$, concave in $\mathrm{RV}$; anteroventral slope broadly convex with 16 small spinose denticles in LV; apex well above mid-height. Posterior bluntly caudate in LV; slightly more cavolate in RV; extremity well below mid-height; posterodorsal slope gently convex in posteroventral slope convex with approximately 15 , small spinose denticles. Stong posterior caudal spine in LV. Dorsal margin strongly convex in $\mathrm{LV}$; straight in RV; cardinal angles rounded in LV, pronounced in RV. Ventral margin biconvex; obscured by lateral inflation particularly in LV. Maximum length well below mid-height; maximum height median in $\mathrm{LV}$, at anterior $1 / 3$ of length in $\mathrm{RV}$; maximum width median. Valve surface with very fine and sparse punctae in adult and $\mathrm{A}-1$ juvenile; strong punctae in younger juveniles. Internal features typical of Paranesidea.

Dimensions $(\mathrm{mm})$

\begin{tabular}{clrrr} 
Holotype LV & 1986.491 & 17 & 1.24 & 0.90 \\
Paratype RV & 1986.492 & 15 & 1.14 & 0.77 \\
Paratype LV & 1986.493 & 16 & 1.11 & 0.80 \\
Paratype RV & 1986.494 & 30 & 1.11 & 0.71 \\
Paratype LV & RT/SIR/102 & 17 & 1.12 & 0.81 \\
Paratype RV & RT/SIR/103 & 19 & 1.17 & 0.78 \\
Paratype RV & A-2 1986.495 & 56 & 0.66 & 0.45 \\
Paratype LV & RT/SIR/105 & 1 & 1.21 & 0.91 \\
Paratype RV & RT/SIR/106 & 1 & 1.17 & 0.78 \\
Mean and range of dimensions (mm) & length & \multicolumn{3}{c}{ height } \\
6 LV & \multicolumn{1}{c}{ l.16 (1.12-1.25) } & $0.85(0.81-0.92)$ \\
15 RV & $1.13(1.07-1.20)$ & $0.75(0.68-0.80)$
\end{tabular}

\section{Explanation of Plate 8}

Figs. 1-9. Paranesidea? paucipunctata sp. nov.: fig. 1, Holotype $1986.491 \mathrm{LV}$, ext. lat. $(\times 33)$; fig. 2, Paratype 1986.492 RV, ext. lat. (×32); fig. 3, Paratype 1986.493 LV, int. lat. $(\times 31)$; fig. 4, Paratype $1986.494 \mathrm{RV}$, int. lat. (×37); fig. 5, Paratype 1986.495 A-2 RV, ext. lat. (×39); fig. 6, Paratype $1986.494 \mathrm{RV}$, detail of hinge $(\times 71)$; fig. 7, Paratype $1986.493 \mathrm{LV}$, detail of hinge $(\times 74)$; fig. 8 , Paratype $1986.494 \mathrm{RV}$, detail of hinge ( $\times 193)$; fig. 9, Paratype 1986.494 RV, detail of central muscle scars $(\times 156)$.

Figs. 10-17. Pterobairdia briggsae McKenzie: fig. 10, RT/SIR/135 LV, ext. lat. $(\times 60)$; fig. 11, RT/SIR/136 RV, ext. lat. ( $\times 64)$; fig. $12, \mathrm{RT} / \mathrm{SIR} / 139 \mathrm{~A}-1 \mathrm{LV}$, ext. lat. $(\times 65)$; fig. $13, \mathrm{RT} / \mathrm{SIR} / 137 \mathrm{LV}$, int. lat. $(\times 62)$; fig. 14, RT/SIR/138 RV, int. lat. $(\times 63)$; fig. 15, RT/SIR/137 LV, detail of central muscle scars $(\times 345)$; fig. 16 , RT/SIR/137 LV, detail of hinge $(\times 292)$; fig. 17 , RT/SIR/135 LV, detail of ornament on ala $(\times 632)$. 


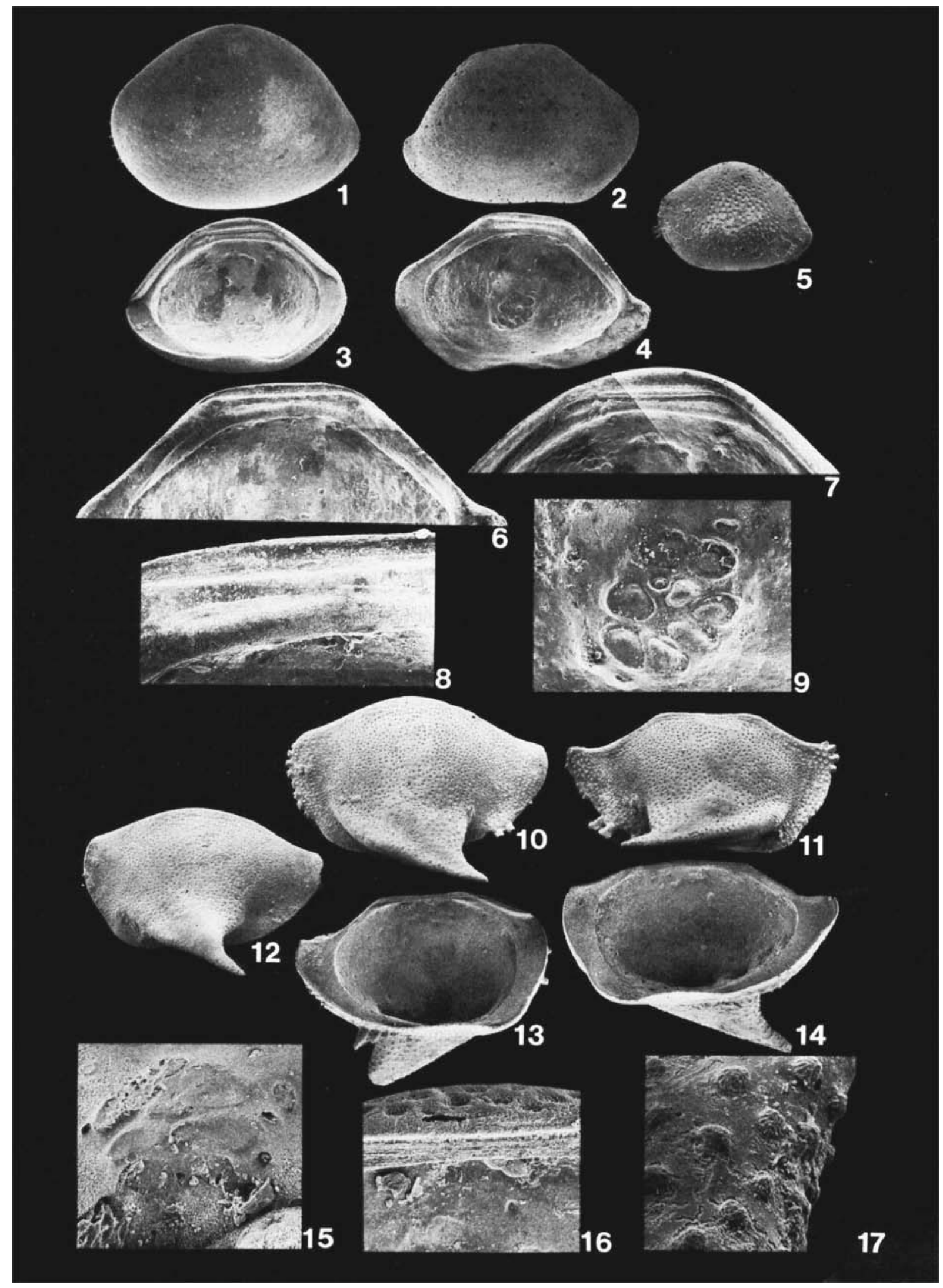


20 LV A-1 $0.90(0.88-0.94)$

11 RV A-1 $0.88(0.84-0.92)$

10 LV A-2 $0.68(0.65-0.72)$

10 LV A-3 $0.52(0.49-0.56)$

10 LV A-4 $0.40(0.38-0.46)$

$0.64(0.61-0.67)$

$0.58(0.54-0.61)$

$0.46(0.45-0.49)$

$0.34(0.33-0.37)$

$0.26(0.25-0.28)$

Remarks. The shape of the LV and the fine ornament of the adults and $\mathrm{A}-1$ juveniles of this species are not typical of Paranesidea although the $\mathrm{A}-2$ and younger juveniles are more typical of the genus. The central muscle scars pattern of this species, however, is typical of Paranesidea. The present species conforms fairly closely with Brady's (1880) original description and illustrations of Bairdia globulus but differs principally in the pattern of the opaque patches and in shape. Hartmann (1978) illustrated a RV of an unnamed species of Bairdia from the northwest coast of Australia, which is similar, but is more strongly caudate posteriorly and more strongly punctate.

The large range in size of the adults and $A-1$ juveniles may reflect sexual and precocious sexual dimorphism, although the sizes do not fall into distinct clusters.

Distribution. Samples: $1,2,13,14,15,16,17,19,29$, $30,32,45,56,57,58$, Guadalcanal.

Genus Pterobairdia McKenzie \& Keij, 1977 Pterobairdia briggsae McKenzie, 1986

(Fig. 6, Nos. 12-13; Pl. 8, Figs. 10-17)

1986 Pterobairdia briggsae sp. nov. McKenzie: 92, 93, pl. 1, figs. 1-7.

Material. 17 specimens: 10 adults and 7 juveniles to A-3.

Dimensions (mm)

\begin{tabular}{llccccc} 
& & & & \multicolumn{3}{c}{$\begin{array}{c}\text { width } \\
\text { (across }\end{array}$} \\
LV & RT/SIR/135 & Sample length height & ala) \\
RV & RT/SIR/136 & OS6 & 0.77 & 0.44 & 0.49 \\
LV & RT/SIR/137 & OS6 & 0.74 & 0.37 & 0.41 \\
RV & RT/SIR/138 & OS6 & 0.79 & 0.40 & \\
LV & A-1 & RT/SIR/139 & OS6 & 0.65 & 0.39 &
\end{tabular}
RV A-2
$\begin{array}{lll}\text { OS6 } & 0.54 & 0.27\end{array}$
LV A-3
$\begin{array}{lll}\text { OS6 } & 0.44 & 0.26\end{array}$

Remarks. This is only the second species of the genus to be described. It may be distinguished from the type species $P$. maddocksae McKenzie \& Kiej, 1977, described from Holocene and Recent sediments from Onotoa, Gilbert Islands and the Flores Sea by the fact that in the type species the dorsal surface of the alae are covered with coarse pustules which are absent in the present species. In the latter, the alae are somewhat more recurved, and the nature of the anterodorsal and posteroventral marginal denticles in the two species is also distinct, those of the type species being more regular and less strongly developed.

Distribution. Sample OS6, Shortland Island. The type material is from the Ontong Java Lagoon.

Genus Triebelina Bold, 1946

Triebelina bradya Triebel, 1948

(Pl. 9, Figs. 1-8)

1890 Bairdia truncata (non. Kirkby); Brady: 494, pl. 2, figs. $1-2$.

1946 Triebelina sp. Bold: 78.

1948 Triebelina bradyi sp. nov. Triebel: 18.

1969 Triebelina bradyi Triebel; Maddocks: 63, pl. 2, figs. 3 ; figs. $32 \mathrm{a}, 33 \mathrm{a}-\mathrm{d}$.

1974 Triebelina bradyi Triebel; Keij: 352, pl. 2, figs. $13-14$.

1977 Triebelina bradyi Triebel; McKenzie \& Keij: 372. Material. 27 specimens: 18 adults and 9 juveniles to A-3.

Dimensions ( $\mathrm{mm})$

$\begin{array}{lrccc} & & \text { length } & \text { height } & \text { width } \\ \text { RV } & \text { RT/SIR/107 } & 0.67 & 0.32 & \\ \text { LV } & \text { RT/SIR/108 } & 0.57 & 0.30 & \\ \text { Car. } & \text { RT/SIR/112 } & 0.54 & 0.30 & 0.24 \\ \text { LV } & \text { A-1 } & 0.53 & 0.32 & \\ \text { RV } & \text { A-1 } & 0.55 & 0.30 & \\ \text { RV } & \text { A-2 } & 0.44 & 0.24 & \\ \text { LV } & \text { A-3 } & 0.37 & 0.22 & \end{array}$

\section{Explanation of Plate 9}

Figs. 1-8. Triebelina bradyi Triebel: fig. 1, RT/SIR/108 LV, ext. lat. $(\times 74)$; fig. 2, RT/SIR/107 RV, ext. lat. $(\times 76)$; fig. 3, RT/SIR/110 LV, int. lat. ( $\times 48)$; fig. 4, RT/SIR/112 Car, ext. dorsal $(\times 90)$; fig. 5, RT/SIR/107 RV, int. lat ( $\times 72)$; fig. 6, RT/SIR/108 LV, detail of lateral ornament $(\times 358)$; fig. $7, \mathrm{RT} / \mathrm{SIR} / 107 \mathrm{RV}$, detail of central muscle scars $(\times 198)$; fig. 8 , RT/SIR/107 RV, detail of hinge $(\times 115)$.

Figs. 9-14. Triebelina sertata Triebel: fig. 9, RT/SIR/114 Car, ext. lat. of LV $(\times 59)$; fig. 10, RT/SIR/113 RV, ext. lat. $(\times 90)$; fig. $11, \mathrm{RT} / \mathrm{SIR} / 115 \mathrm{LV}$, int. lat. $(\times 77)$; fig. 12, RT/SIR/114 Car,ext. dorsal $(\times 92)$; fig. 13, RT/SIR/116 RV, int. lat. $(\times 71)$; fig. 14 , RT/SIR/113 RV, detail of lateral ornament $(\times 451)$.

Figs. 15-19. Mydionobairdia schyroconcha Maddocks: fig. 15, RT/SIR/118 LV, ext. lat. (×74); fig. 16, RT/SIR/117, RV, ext. lat. $(\times 92)$; fig. $17 \mathrm{RT} / \mathrm{SIR} / 117 \mathrm{RV}$, detail of lateral ornament and normal pore $(\times 2307)$; fig. 18 , $\mathrm{RT} / \mathrm{SIR} / 118 \mathrm{LV}$, int. lat. $(\times 69)$; fig. $19, \mathrm{RT} / \mathrm{SIR} / 119 \mathrm{RV}$, int. lat. $(\times 72)$. 


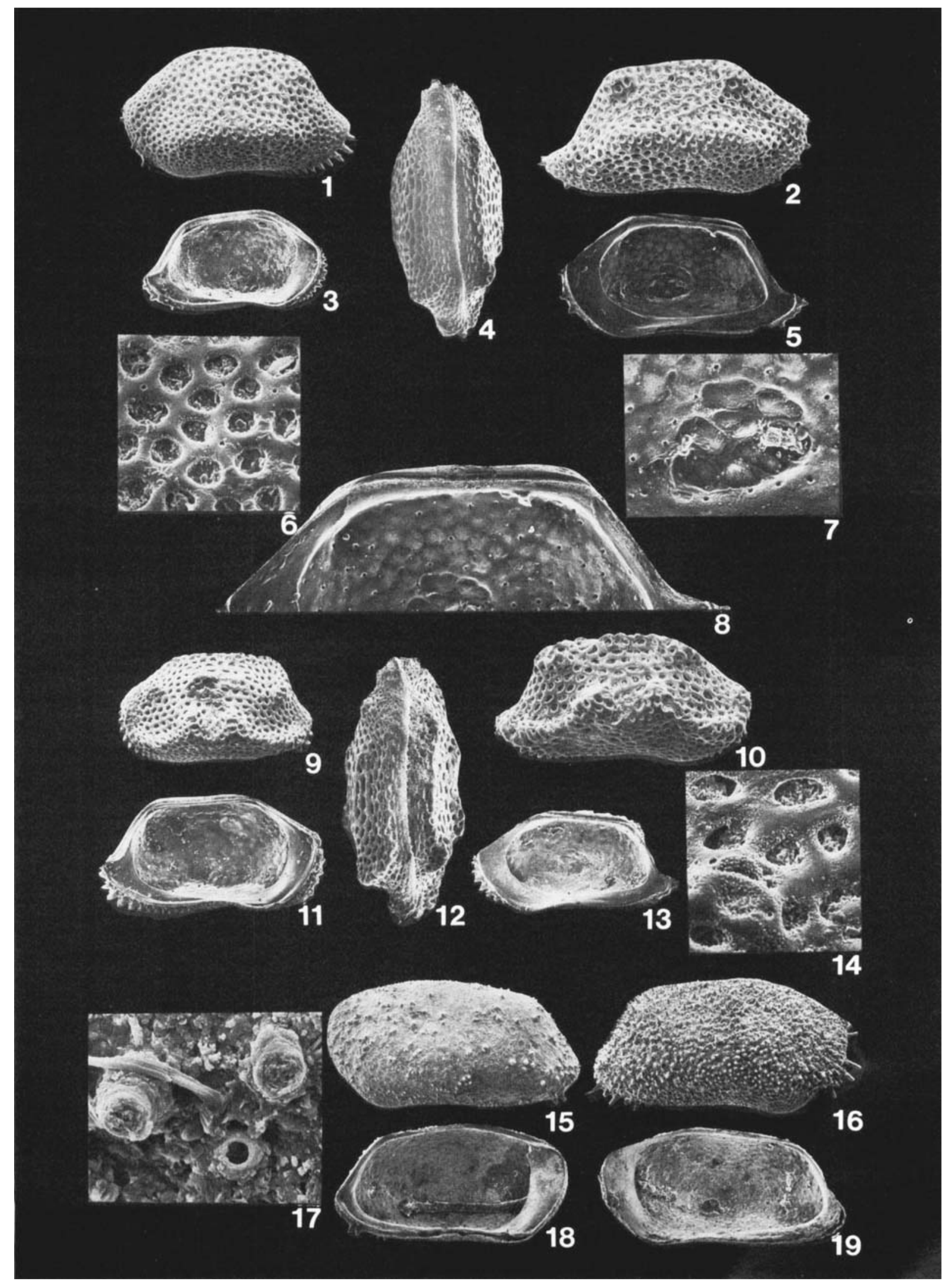


Remarks. Triebelina sertata Triebel, 1948 is more strongly inflated dorsolaterally and the ventrolateral swellings are sited further from the anterior and posterior. Triebelina reticulopunctata Benson, 1959, from the Recent of Todos Santos Bay, California is less inflated mediolaterally and lacks swellings at the cardinal angles.

Distribution. Uppermost Miocene - Lower Pliocene; Fiji (Keij, 1974). Pleistocene; Midway Island (Holden, 1976).

Holocene - subfossil; Onotoa, Gilbert Islands (McKenzie \& Keij, 1977); Batu Island off W. Sumatra (Bold, 1950); Nosy Bé, Madagascar (Maddocks, 1969).

Recent; Nouméa, New Caledonia and Upolu, Samoa (Brady, 1890): Seran, Irian (Sarong) and Tanimbar Island in the East Indonesian Seas (Keij, 1953): South China Sea near Lucania Shoals (Keij, 1974 and Nosy Bé, Madagascar (Maddocks, 1969).

Samples: 1, 2, 13, 14, 17, 61, OS5, OS6, Guadalcanal and Shortland Islands.

Triebelina sertata Triebel, 1948

(Pl. 9, Figs. 9-14)

1946 Triebelina indopacifica Bold (pars): 74.

1948 Triebelina sp. cf. Triebelina cubensis Bold; Kingma: 69 , pl. 7 , fig. 4.

1948 Triebelina sertata sp. nov. Triebel: 19, figs. 1-2.

1969 Triebelina sertata Triebel; Maddocks: pl. 61, figs. $31,32 \mathrm{~b}-\mathrm{e}$.

1974 Triebelina sertata Triebel; Keij: 356, pl. 2, figs. 6-12.

Material. 14 specimens: 13 adults, $1 \mathrm{~A}-2$ juvenile. Dimensions (mm)

$\begin{array}{lrcc} & & \text { length } & \text { height } \\ \text { RV } & \text { RT/SIR/113 } & 0.54 & 0.26 \\ \text { Car. } & \text { - LV RT/SIR/114 } & 0.58 & 0.31 \\ & \text { - RV RT/SIR/114 } & 0.54 & 0.26 \\ \text { LV } & \text { A-2 } & 0.40 & 0.22\end{array}$

Remarks. This species is most similar to $T$. indopacifica Bold, 1948 but the ventrolateral carina is not thickened over the muscle scar area but swollen onto 2 nodes which are sited on either side. The mid-lateral ridge of $T$. indopacifica is more strongly developed and swollen into nodes at its extremities and the reticula fossae are more rounded in shape.

Distribution: Upper Miocene; Cebu, Philippines (Keij, 1974).

Lower Pliocene; Andaman Islands (Guha, 1968): Northern Sumatra (Kingma, 1948).

Recent, cosmopolitan: Caribbean (Puri, 1960; Teeter, 1973; Bold, 1946): Clipperton Island and Fiji (Allison \& Holden, 1971): Nosy Bé and Tulear, Madagascar (Maddocks, 1969): Red Sea (Triebel, 1948; Keij, 1974): Massawa, Ethiopia; Cyprus and the Persian Gulf (Keij, 1974): Reunion Island, S.W. Indian
Ocean (Keeler, 1981, MS).

Samples: 14, 57, OS5, OS6, Guadalcanal and Shortland Islands.

\section{Mydionobairdia Gen. nov.}

Type species. Triebelina schyroconcha Maddocks, 1969. Derivation of name. Gr. Mydion a boat. From the overall resemblance of this genus to a boat.

Diagnosis. A small robust genus of the Bairdiinae, subrhomboidal in lateral view, subcylindrical to subelliptical in dorsal view. Anterior margin with long convex antero-ventral slope and apex above mid height ; posterior margin with subventral apex and long straight or slightly concave posterodorsal slope. Dorsal surface covered with small spines and papillae. Long thin marginal spines anteriorly and posteroventrally. Hinge adont, narrow. Auxiliary dentition absent. Adductor muscle scars usually 8 in two obliquely curved rows.

Remarks. This genus is closely related to Triebelina but differs in its more elongate and subrhomboidal shape and in lacking the ribs and strong punctate or reticulate ornament of that genus. From Papillatabairdia Bentley (1981) it differs in shape (this genus being reniform with a rounded anterior and subrounded posterior margins) and in ornament, Papillatabairdia being densely covered with very small hemispherical papillae.

Keij (1974, p. 346) doubted that Triebelina schyroconcha belonged to Triebelina because of its unusual shape and ornament.

There are other species in the subfamily which somewhat resemble $M$. schyroconcha in shape, such as Bairdia hanaumaensis Holden, 1967, from the late Cainozoic and Recent of Hawaii, but this species is densely and minutely punctate. Bairdia sp., Allison \& Holden, 1971, while similar in shape, is punctate. These two species and a number of as yet undescribed species known to one of us (RCW) from Indonesia could be subsequently included in Mydionobairdia if the diagnosis was amended to embrace punctate species.

Bold, 1966 illustrated two species; B. tuberculata Brady and $B$. sp. aff. tuberculata Brady (Recent, Panama) which are of a similar rhomboidal shape and possess antero- and posteroventral marginal spines, but are punctate. These two species also may be included in Mydionobairdia if the diagnosis is emmended to included punctate forms.

Mydionobairdia schyroconcha (Maddocks, 1969) (Pl. 9, Figs. 15-19)

?1880 Bairdia tuberculata Brady; Brady, 60, pl. 10, figs. 3a-d.

?1890 Bairdia tuberculata Brady; Brady, 495. 
1969 Triebelina schyroconcha sp. nov. Maddocks : 65 , pl. 2, figs. $7-8$; figs. $33 \mathrm{~g}-\mathrm{h}$.

1974 Triebelina schyroconcha Maddocks; Keij, pl. 1, fig. 7.

?non 1867 Bairdia tuberculata Brady (= Bairdia rhomboidea Brady (non Kirkby).

non 1966 Bairdia tuberculata Brady: Bold, pl. 2, figs. $3 a-6$.

Materials. 6 specimens, 3 adults, 3 juveniles.

Dimensions (mm)

$\begin{array}{llcc} & & \text { length } & \text { height } \\ \text { RV } & \text { RT/SIR/117 } & 0.55 & 0.28 \\ \text { LV } & \text { RT/SIR/118 } & 0.63 & 0.32 \\ \text { A-1 } & \text { RV } & 0.56 & 0.27 \\ \text { A-2 LV } & & 0.42 & 0.22 \\ \text { A-3 } & \text { RV } & 0.36 & 0.18\end{array}$

Remarks: Brady (1867, p. 162 , pl. 19, figs. 14, 15) described Bairdia rhomboidea, from the Recent of Mauritius as sybrhomboidal in shape and possessing a punctate surface ornament. In 1880 he redescribed $B$. tuberculata $(=B$. rhomboidea Brady, 1867 (non Kirkby)) from the Recent of the Admiralty Islands. Despite remarking that the species is exactly like that from Mauritius, he described $B$. tuberculata as "rather rough, with small closely-set tubercular prominences" and not punctate.

Triebelina schyroconcha Maddocks, 1969 (Recent, Madagascar) is considered by her to be questionably synonymous with $B$. tuberculata Brady of Brady, 1880 and 1890 , but not with $B$. tuberculata Brady, $1867(=B$. rhomboidea Brady (non Kirkby)). The species illustrated by Maddocks is almost certainly conspecific with the present material and material from the Java Sea (Karen Watson pers. comm., 1986).

Hartmann (1978, 1981) illustrates a species he assigned to Bythocypris from the Recent of Australia, which resembles the present species in possessing a spinose ornament, but it is less acuminate posteriorly. This species should be included in Mydionobairdia.

In the present study $M$. schyroconcha was recovered from samples 1, 14, 58 in Honiara Bay, Guadalcanal and sample OS6, Shortland Island.

\section{ACKNOWLEDGEMENTS}

The authors wish to thank Dr. G. W. Hughes and Mr. C. C. Turner who most kindly collected the samples on which this study is based. We also would like to thank Dr. C. W. Haskins and Karen Watson for reading the manuscript and Mrs. S. Achterberg for typing it.

Financial assistance for this research has been provided by Robertson Research International Limited.

Manuscript received September 1986

Revised manuscript accepted January 1988

\section{REFERENCES}

Allison, E. C. \& Holden, J. C. 1971. Recent ostracodes from Clipperton Island, eastern tropical Pacific. Trans San Diego Soc. Nat. Hist., 16(7), 165-124.

Benson, R. H. 1959. Ecology of Recent ostracodes of the Todos Santos Bay region, Baja California, Mexico. Univ. Kansas Paleont. Contrib., Arthropoda: art., 1; 80 pp.

Bentley, C. 1981. Papillatabairdia, A New Ostracod Genus from Brisbane Water, New South Wales. Journal and Proceedings, Royal Society of New South Wales, 114, 59-61.

Bold, W. A., van den. 1946. Contribution to the study of Ostracoda, with special reference to the Tertiary and Cretaceous microfauna of the Caribbean region. (Utrecht Univ. thesis), Amsterdam, 8-167.

Bold, W. A., van den. 1950. Hemikrithe, a new genus of Ostracoda from the Indo-pacific. Ann. Mag. Nat. Hist. ser. $12,3(34)$, 900-904.

Bolz, H. 1969. Der "bairdoppilate" Verschluss und SkulpturUnterschiede bei Bairdien (Ostrac.) der alpinen Obertrias. Senck. Lethaea, 50(5/6), 411-431.

Bolz, H. 1971. Late Triassic Bairdiidae and Healdiidae. In Oertli, H. J. (Ed.), Paléoécologie Ostracodes. Bull. Centre Rech. Pau-SNPA, 5 suppl., 717-745.

Brady, G. S. 1880. Report on the Ostracoda dredged by H.M.S. Challenger during the years 1873-1876. Rept. Voyage Challenger, Zool., 1(3), 184 pp.

Brady, G. S. 1890 . On Ostracoda collected by H. B. Brady Esq., LL.D., F.R.S. in the South Sea Islands. Trans. Roy. Soc. Edinburgh, 35(2), no. 14, 489-525.

Chapman, F. 1902a. On some Foraminifera and Ostracoda from Cocos Keeling Atoll, collected by Dr. C. W. Andrews, 1898. Proc. Zool. Soc. London, 1, 228-233.

Chapman, F. 1902 b. On some Ostracoda from Funafuti. Jour. Linn. Soc. London, Zool., 28(184), 417-433.

Chapman, F. 1906. On Some Foraminifera and Ostracoda obtained off Great Barrier Island, New Zealand. Trans. Proc. New Zealand Inst. 38, 77-112.

Chapman, F. 1910. On the Foraminifera and Ostracoda from soundings (chiefly deep-water) collected round Funafuti by H.M.S. Penguin. Jour. Linn. Soc. London, Zool., 30(202), 388-474.

Coryell, H. N., Sample, C. H. \& Jennings, P. H. 1935. Bairdoppilata, a new genus of Ostracoda, with two new species. American Mus. Novitates, 777, 1-5.

Fyan, E. C. 1916. Some young-Pliocene ostracodes of Timor. Proc. Koninkl. Neder. Akad. Wetenschappen. Amsterdam Sec. Sci., 18(2/7), 1205-1217.

Guha, D. K. 1968. On the Ostracoda from Neogene of Andaman Islands. Jour. Geol. Soc. India, 9(1), 58-66.

Harding, J. P. 1962. Mungava munda and four other new species of ostracod crustaceans from fish stomachs. Nat. Hist. Rennell Island, British Solomon Islands, Copenhagen, 4, 51-62.

Hartmann, G. 1959. Zur Kenntnis der lotischen Lebensbereiche der pazifischen Küste von El Salvador unter besonderer Berücksichtigung seiner Ostracodenfauna. (III. Beitrag zur Fauna El Salvadors). Keil. Meeres, 15(2), $187-241$.

Hartmann, G. 1978. Die Ostracoden der Ordnung Podocopida G. W. Muller, 1894 der tropisch-subtropischen Westküste Australiens (zwischen Derby im Norden und Perth im Suden). In Hartmann-Schroder G. \& Hartmann, G. Zur Kenntnis des Eulitorals der australischen Küsten unter 
besonderer Berücksichtigung der Polychaeten und Ostracoden. Teil 1. Mitt. hamb. zool. Mus. Inst., 75, 64-219.

Hartmann, G. 1979. Die Ostracoden der Ordnung Podocopida G. W. Müller, 1894 der warm-temperierten (antiborealen) West- und Südwestküste Australiens (zwischen Perth im Norden und Eucla im Süden). Tiel 3. Mitt. hamb. zool. Mus. Inst., 76, 219-301.

Hartmann, G. 1980. Die Ostracoden der Ordnung Podocopida G. W. Müller, 1894 der warmtemperieten und subtropisch-tropischen Kustenabschnitte der Süd- und Südostküste Australiens (zwischen Ceduna im Western und Lakes Entrance in Osten). Mitt. hamb. zool. Mus. Inst., 77, 111-204.

Hartmann, G. 1981. Die Ostracoden der Ordnung Podocopida G. W. Müller, 1894 der subtropisch-tropischen Ostküste Australiens (zwischen Eden im Süden und Heron-Island im Norden). Mitt. hamb. zool. Mus. Inst., 78, 97-149.

Hartmann, G. 1982. Beitrag zur Ostracodenfauna Neuseelands (mit einem Nachtrag zue Ostracodenfauna der Westküste Australiens). Mitt. hamb. zool. Mus. Inst., 79, 119-150.

Holden, J. C. 1967. Late Cenozoic ostracodes from the drowned terraces in the Hawaiian Islands. Pacific Sci., 21(1), 1-50.

Holden, J. C. 1976. Late Cenozoic Ostracoda from Midway Island Drill Holes. Geol. Surv. Prof., Paper 680-F, 40 pp.

Hughes, G. W. 1973. Recent Foraminifera from the Solomon Islands. Unpub. Magister thesis, University College of Wales, 81 pp.

Hughes, G. W. 1977a. The Geology and foraminiferal Micropalaeontology of the Lungga and Itina Basin areas of Western Guadalcanal, Solomon Islands. Unpub. Doctorate thesis, University College of Wales, $401 \mathrm{pp}$.

Hughes, G. W. 1977b. Recent Foraminifera from the Honiara Bay area, Solomon Islands. Jour. Foram. Res., 7(1), 45-57.

Keeler, N. P. 1981. Recent Podocopid Ostracoda from Agulhas Bank, South African Continental Margin and Reunion Island, Southern Indian Ocean. Unpub. Magister thesis, University College of Wales, $251 \mathrm{pp}$.

Keij, A. J. 1953. Preliminary note on the Recent Ostracoda of the Snellius Expedition. Proc. Koninkl. Neder. Akad. Wetenschappen, Amsterdam, ser. B, 56(2), 155-168.

Keij, A. J. 1974. Review of the Indopacific species of Triebelina (Ostracoda). Proc. Kononkl. Neder. Akad. Wetenschappen, Amsterdam, ser. B, 77(4), 345-358.

Keij, A. J. 1976. Note on Havanardia and Triebelina species (Ostracoda). Proc. Koninkl. Neder. Akad. Wetenschappen, Amsterdam, ser. B, 79(1), 36-44.

Kingma, J. Th. 1948. Contributions to the knowledge of the Young Caenozoic Ostracoda from the Malayan Region. (Utrecht, Univ. thesis), Kemink Printers, Utrecht, 119 pp.

Kollmann,, K. 1960. Ostracoden aus der alpinen Trias Osterreichs; 1 - Parabairdia n.g. und Ptychobairdia n.g. (Bairdiidae). Geol. Bund. Jahrb., 5, 79-105.

Kollman, K. 1963. Ostracoden aus der alpinen Trias. 2 Weitere Bairdiidae. Geol. Bund. Jahrb., 106(1), 121-203.

Korniker, L. S. 1961. Ecology and taxonomy of Recent Bairdiinae (Ostracoda). Micropalaeontology, 7(1), 55-70.

Kristan-Tollmann, E. 1969. Zue stratigraphischen Reichweite der Ptychobairdien und Anisobairdien (Ostracoda) in der alpinen Trias. Geol. Pal., no. 3, 81-95.

Kristan-Tollmann, E. 1970. Einige neue Bairdien (Ostracoda) aus der alpinen Trias. N. Jb. Geol. Palaeont. Abh., 135(3), 268-310.
Maddocks, R. F. 1966. Distribution patterns of living and subfossil podocopid ostracodes in the Nosy Bé Area, northern Madagascar. Univ. Kansas Paleont. Contrib. , art. 12, 77 pp.

Maddocks, R. F. 1969. Revision of Recent Bairdiidae (Ostracoda). U.S. National Mus. Bull., no. 295, 126 pp.

Maddocks, R. F. 1986. Podocopid Ostracoda of Bermudian Caves. Stygologia, 2(1/2), 26-76.

McKenzie, K. G. 1986. A comparative study of collections from the S.W. Pacific (Saipan to Tonga), with the descriptions of Gambiella caudata (Brady, 1890) and a new species of Pterobairdia (Ostracoda). Jour. of Micropalaeont., 5(1), 91-108.

McKenzie, K. G. \& Keij. A. J. 1977. Pterobairdia (Ostracoda, Bairdiidae). A new Genus from the Indo-west Pacific. Proc. Koninkl. Neder. Akad. Wetenshcappen, Amsterdam, ser $B, \mathbf{8 0}(5), 368-374$.

Morkhoven, F. P. C. M., van. 1958. On the validity of the Ostracod gen. Glyptobairdia and Bairdoppilata. Jour. Paleont., 32(2), 366-368.

Puri. H. S. 1960. Recent Ostracods from the West coast of Florida. Trans Gulf Coast Assoc. Geol. Soc., 10, 107-149.

Puri, H. S. \& Hulings, N. C. 1976. Designation of lectotypes of some ostracods from the "Challenger" Expedition. Bull. British Mus. Nat. Hist. (Zool.), 29(5), 249-315.

Teeter, J. W. 1973. Geographic distribution and dispersal of some Recent shallow-water marine Ostracoda. Ohio Jour. Sci., 73(1), 46-54.

Titterton, R. 1984. The Taxonomy, Ecology and Distribution of Recent Ostracoda from the Solomon Islands. Unpub. Doctorate thesis, University College of Wales, $953 \mathrm{pp}$.

Triebel, E. 1948. Zue Kenntnis der Ostracoden - Gattung Triebelina. Senck. Lethaea, 29(1/6), 17-22.

Watson, K. (in press). Taxonomy, Environmental Distribution, Zoogeographic Significance of Recent Reef Ostracoda, Pilau Seribu, Java Sea.

Whatley, R. C. \& Titteton, R. 1981. Some new Recent podocopid Ostracoda from the Solomon Islands Southwest Pacific. Rev. Espanola de Micropaleont., 13(2), 157-170.

Williams, E. U. 1980. Some Quaternary Ostracods from the Solomon Islands. Unpub. Magister thesis, University College of Wales, $198 \mathrm{pp}$. 